\title{
Laboreal
}

Volume $17 \mathrm{~N}^{\circ} 2$ | 2021

Trabalho e Território

\section{Articular atividade de trabalho e construção territorial da atividade para compreender e transformar o uso de produtos fitofarmacêuticos e dos seus protagonistas}

Articular la actividad de trabajo y la construcción de la actividad para comprender y transformar el uso de productos fitofarmacéuticos y de sus protagonistas

Relier activité de travail et construction territoriale de l'activité pour comprendre et transformer l'usage des produits phytopharmaceutiques et ses protagonistes Articulating work activity and territorial construction of the activity to understand and transform the use of phytopharmaceutical products and their protagonists

Fabienne Goutille e Alain Garrigou

\section{(2) OpenEdition}

Journals

Edição electrónica

URL: https://journals.openedition.org/laboreal/18237

DOI: $10.4000 /$ laboreal.18237

ISSN: 1646-5237

Editora

Universidade do Porto

Refêrencia eletrónica

Fabienne Goutille e Alain Garrigou, «Articular atividade de trabalho e construção territorial da atividade para compreender e transformar o uso de produtos fitofarmacêuticos e dos seus protagonistas», Laboreal [Online], Volume 17 №2 | 2021, posto online no dia 01 dezembro 2021, consultado o 05 dezembro 2021. URL: http://journals.openedition.org/laboreal/18237 ; DOI: https://doi.org/10.4000/ laboreal. 18237

Este documento foi criado de forma automática no dia 5 dezembro 2021.

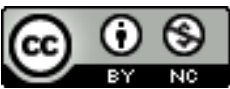

Laboreal está licenciado com uma Licença Creative Commons - Atribuição-NãoComercial 4.0 Internacional. 


\section{Articular atividade de trabalho e construção territorial da atividade para compreender e transformar o uso de produtos fitofarmacêuticos e dos seus protagonistas}

Articular la actividad de trabajo y la construcción de la actividad para comprender y transformar el uso de productos fitofarmacéuticos y de sus protagonistas

Relier activité de travail et construction territoriale de l'activité pour comprendre et transformer l'usage des produits phytopharmaceutiques et ses protagonistes

Articulating work activity and territorial construction of the activity to understand and transform the use of phytopharmaceutical products and their protagonists

Fabienne Goutille e Alain Garrigou

NOTA DO EDITOR

Autor correspondente : Fabienne Goutille

Traduzido por :

Teresa Lello (tlello12@gmail.com)

Christiano Lello

Manuscrito recebido em : 30/06/2021

Aceite após peritagem : 27/09/2021 


\section{Introdução}

Este artigo apresenta uma investigação-intervenção em que se recorreu à noção de território para compreender e transformar o trabalho que é realizado em meio vitícola. Foi dada particular atenção aos mecanismos e práticas sociais que determinam a organização territorial nacional e local da utilização de produtos fitofarmacêuticos. Pretende-se mostrar como esta dimensão contextual da atividade de tratamento fitossanitário ultrapassa os limites da ergonomia e as questões a serem abordadas para acompanhar os viticultores na prevenção dos riscos dos pesticidas.

2 Nos últimos sessenta anos, a agricultura francesa foi construída com base na utilização de pesticidas (Gatignol \& Étienne, 2010). Os pesticidas são aí apresentados como essenciais para reduzir a ação das pragas e responder às expectativas dos consumidores em termos de produtividade, qualidade e aparência irrepreensível dos produtos vegetais. Os especialistas afirmam que os pesticidas continuarão a desempenhar um papel na agricultura na medida em que permitem evitar perdas significativas nas culturas (Aubertot et al., 2005). Isto é particularmente verdade no sector vitícola, o segundo sector excedentário nacional (depois da aeronáutica) e o primeiro sector excedentário agroalimentar (FranceAgriMer, 2019) [1] que, enquanto símbolo da economia francesa, tem de evitar perdas.

3 No território francês, a utilização de pesticidas agrícolas é, hoje em dia, controversa dadas as crescentes provas dos danos que podem causar ao meio ambiente e à saúde (Aubertot et al., 2005). Os pesticidas, alguns dos quais proibidos há vários anos em França, podem ser encontrados em todo o meio ambiente (ambientes aquáticos, solo, ar dentro e fora dos edifícios) (Gatignol \& Étienne, 2010). Vários estudos epidemiológicos e toxicológicos (Baldi et al., 2021) vieram demonstrar a existência de uma relação desses pesticidas com o aparecimento de patologias graves (linfoma não Hodgkin, mieloma múltiplo, cancro da próstata, doença de Parkinson e Alzheimer, distúrbios reprodutivos, ansiedade, depressão, etc.).

Os agricultores franceses são simultaneamente vítimas da exposição a pesticidas e responsáveis por ela. Enquanto principais utilizadores de pesticidas, os agricultores constituem uma das populações de maior risco e das mais atingidas pelos efeitos que os pesticidas têm sobre a saúde (Baldi et al., 2021). Enquanto principais consumidores de pesticidas, visto que a maior parte das vendas de substâncias ativas se destina a usos agrícolas [2], eles são os grandes culpados da presença generalizada de pesticidas. Nesse contexto, é cada vez mais vasta a regulamentação do uso de pesticidas e das práticas dos agricultores no território francês (Jas, 2010) [3].

5 Atualmente, a política francesa de gestão dos riscos dos pesticidas assenta numa avaliação da exposição aos pesticidas feita com base em modelos formais desligados das práticas agrícolas reais (Laurent et al., 2016). Envolver a ergonomia é uma medida fundamental para garantir que as questões relacionadas com o trabalho e a saúde dos agricultores constem da avaliação e da prevenção dos riscos dos pesticidas. A investigação ergonómica levada a cabo consistiu em documentar a exposição durante a realização do trabalho agrícola tal como ele é feito, designadamente através de um estudo não controlado dessa exposição, para confirmar a avaliação dos riscos (antes e depois da autorização de comercialização dos pesticidas) e avaliar a eficácia das respetivas medidas de prevenção. A investigação, com o intuito de transformar, tentou também descobrir como atuar nas situações de risco dos pesticidas identificadas pelos 
profissionais agrícolas envolvidos. Ultrapassou-se, assim, o paradigma dominante segundo o qual os agricultores são os "alvos da prevenção a alcançar" (Garrigou et al., 2012) ao mesmo tempo que se questionou a atividade de trabalho, os seus constrangimentos e dinâmicas territoriais (locais e nacionais) para construir novas soluções de prevenção (Béguin, Dedieu \& Sabourin, 2011 ; Boudra, Delecroix \& Béguin, 2016 ; Pueyo, 2020).

Os resultados da investigação que aqui se apresentam na forma de um estudo de caso decorrem do projeto Prevexpo : Prévenir les Risques Ensemble en milieu Viticole à partir des conditions réelles d'EXPOsition (Prevenir em conjunto os riscos do meio vitícola a partir das condições reais de exposição). Este projeto, financiado pelo Ministério da Agricultura francês e pela Região da Aquitânia, terminou em 2020, ao fim de quatro anos de investigação-intervenção. O projeto, que foi iniciado por investigadores ergonomistas da equipa Epicene (Epidemiologia dos cancros e exposições ambientais), envolveu vários parceiros locais: sindicatos agrícolas, investigadores (em epidemiologia, sociologia e toxicologia química), metrologistas e profissionais do sector vitícola (produtores e assalariados) da região de Bordéus. Depois de um vasto trabalho de campo preliminar (ações de formação com diferentes sindicatos, estágios em explorações vitícolas francesas, estudo dos instrumentos de caracterização de pesticidas), o projeto Prevexpo foi desenvolvido essencialmente com 4 viticultores com práticas de trabalho diversas (organização do trabalho com e sem assalariados, método de cultura convencional agroecológico ou biológico, sócios e não-sócios de adegas cooperativas, equipamento de ponta e trabalho manual, vinhas de 4 a 30 hectares). Esses viticultores (E1, E2, E3 e E5) não só aceitaram que se observassem as suas práticas, mas também contribuíram para a produção de conhecimentos sobre a exposição aos pesticidas e a sua possível transformação.

$\mathrm{O}$ artigo divide-se em cinco partes. Depois de uma breve apresentação da atividade de tratamento fitossanitário em que se centrou a análise (parte 1), apresenta-se a metodologia seguida para documentar as exposições durante o trabalho real e refletir sobre medidas tendentes à sua transformação com as pessoas implicadas nessa atividade (parte 2). A parte 3 apresenta as exposições aos pesticidas identificadas nas situações de trabalho e de vida dos viticultores e dos que lhes estão próximos. A parte 4 analisa a construção territorial da atividade de trabalho em meio vitícola. A última parte, que apresenta os determinantes proximais dessa exposição aos pesticidas relativamente aos quais os viticultores participantes no Prevexpo puderam intervir no âmbito da sua empresa, leva a discutir os determinantes que estão mais distantes dessas exposições para, a partir deles, conceber uma intervenção ergonómica que ajude os agricultores a criar situações de prevenção no território francês.

\section{Tratamento fitossanitário da vinha}

8 A análise apresentada neste artigo incide sobre a atividade de tratamento fitossanitário em ambiente vitícola. Em viticultura, muitas das operações têm como objetivo tratar a vinha para conseguir que ela se desenvolva e dê uvas destinadas à produção de vinho. 0 tratamento fitossanitário da vinha é uma delas e visa eliminar os bioagressores com recurso a produtos sintéticos, produtos minerais como o cobre e o enxofre, ou produtos naturais como extratos de plantas ou micro-organismos, produtos estes que não têm um efeito biocida direto, mas antes um efeito de competição. Estes produtos 
fitofarmacêuticos (pesticidas destinados ao uso agrícola) são aplicados em parcelas de vinha, junto à base das cepas (geralmente em tratamentos herbicidas) ou nas partes aéreas da planta (geralmente nos tratamentos fungicidas ou inseticidas).

A preparação da calda (mistura de produtos fitofarmacêuticos) é necessária para proceder, em seguida, à fertilização (aplicação da calda nas culturas). Esta operação consiste em dosear e misturar num depósito um ou vários produtos fitofarmacêuticos (em pó, líquidos ou granulados) juntamente com água para obter um preparado. Este preparado faz-se e altera-se para cada tratamento, porque vai variando em função da ameaça que se pretende combater (fungos, infestantes, insetos), do estado em que se encontra a planta e do material de preparação e de aplicação. As substâncias ativas utilizadas, as soluções comerciais usadas e as quantidades pretendidas são, portanto, diferentes de calda para calda. Para tratar vinte hectares de vinha, os produtores contactados preparam cem caldas diferentes (dosagem e incorporação dos produtos) com vinte variantes de composição (substâncias ativas, soluções comerciais, ordem de incorporação e quantidade dos produtos a misturar com água).

Nas empresas envolvidas, o tratamento fitossanitário faz-se, em média, de dez em dez dias, todos os anos entre os meses de março e agosto. A realização dos tratamentos corresponde a cerca de trinta dias de trabalho por ano. Todos os viticultores implicados no Prevexpo eram simultaneamente viticultores e preparadores de calda : eles dirigiam, organizavam e realizavam os tratamentos fitossanitários nas suas próprias explorações vitícolas.

11 O número de dias de trabalho gastos no processo de tratamento é muito maior e dificilmente quantificável quando entra em linha de conta o trabalho de gestão que eles fazem. Por exemplo, eles têm de assegurar a gestão dos produtos fitofarmacêuticos : encomenda, compra, armazenamento, acompanhamento dos registos, triagem, reciclagem. Têm de controlar a gestão dos produtos e das alfaias de tratamento: compra, armazenamento, manutenção e limpeza dos recipientes de preparação, dos pulverizadores, das peças mecânicas. Têm a seu cargo a gestão da segurança das pessoas : formação do pessoal, aplicação das normas para locais fitossanitários, escolha e disponibilização dos equipamentos de proteção, respeito dos prazos para regresso do pessoal à vinha depois da fertilização e dos prazos que antecedem a colheita do produto final. São responsáveis pela gestão da poluição : respeito das áreas de não-tratamento, instalação de barreiras vegetais e acompanhamento da força do vento, adaptação e investimento em material de precisão, respeito das condições de armazenamento, de mistura e de eliminação dos produtos, triagem e reciclagem dos equipamentos e águas usados, taxa ecológica. No fundo, têm a seu cargo a gestão mais alargada da proteção parasitária da vinha para garantir a produção e a comercialização do vinho (programas de tratamento, avaliação e acompanhamento da pressão parasitária, escolha das substâncias ativas, composição da calda) na empresa e, de forma mais ampla, na região de Bordéus (obrigatoriedade de tratamento inseticida duas a três vezes por ano, implementação de práticas de "Valor Ambiental Elevado", imagem dos vinhos de Bordéus).

\section{Metodologia da investigação-intervenção}

12 A investigação apresentada neste artigo seguiu o quadro teórico e metodológico da ergotoxicologia (Galey et al., 2019 ; Galey \& Garrigou, 2020). O conceito de atividade foi 
utilizado para melhorar a compreensão das situações de trabalho relacionadas com o tratamento fitossanitário. Procurou-se, assim, documentar a exposição a pesticidas na atividade de trabalho real (contexto e fatores de exposição) durante a operação de tratamento (preparação e aplicação da calda, limpeza dos equipamentos).

Complementarmente, o legado de Oddone parece ser "ainda hoje muito atual e operacional relativamente à forma de produzir conhecimento sobre o trabalho (cf., por exemplo, "comunidade científica alargada"), de conduzir a análise da atividade (ver "instrução ao sósia") e de considerar o lugar de cada pessoa na análise e no diagnóstico da prevenção de riscos em sentido amplo, dentro da empresa e na sociedade" (Re, Callari \& Occelli, 2014, p. 149). Estas palavras de Alessandra Re, colaboradora e mulher de Oddone, constituíram um grande estímulo para, no seio de uma comunidade científica alargada (Oddone, 1984), se propor um desenvolvimento da abordagem ergotoxicológica e para permitir compreender e transformar as situações de risco dos pesticidas.

As observações instrumentais da atividade (filme e metrologia) abrangeram dois a três dias de trabalho completos em cada uma das empresas (entre abril e julho de 2018). Selecionaram-se três técnicas para ajustar o filme da atividade à metrologia dos pesticidas : amostragem por limpeza das superfícies, amostragem com auxílio de tecido absorvente e amostragem atmosférica (ver Figura 1). A partir dessas observações, procurou-se descobrir quais as "substâncias presentes", identificar os "contactos relevantes" e determinar "a ocorrência, duração e frequência desses contactos" (Mohammed-Brahim, 2011). Foi, assim, possível classificar os contactos diretos (com produtos fitofarmacêuticos e seus derivados) e indiretos (com superfícies contaminadas por esses produtos) em condições reais de utilização de produtos fitofarmacêuticos.

Figura 1 : Tipos de amostragens efetuadas no âmbito do Pravexpo

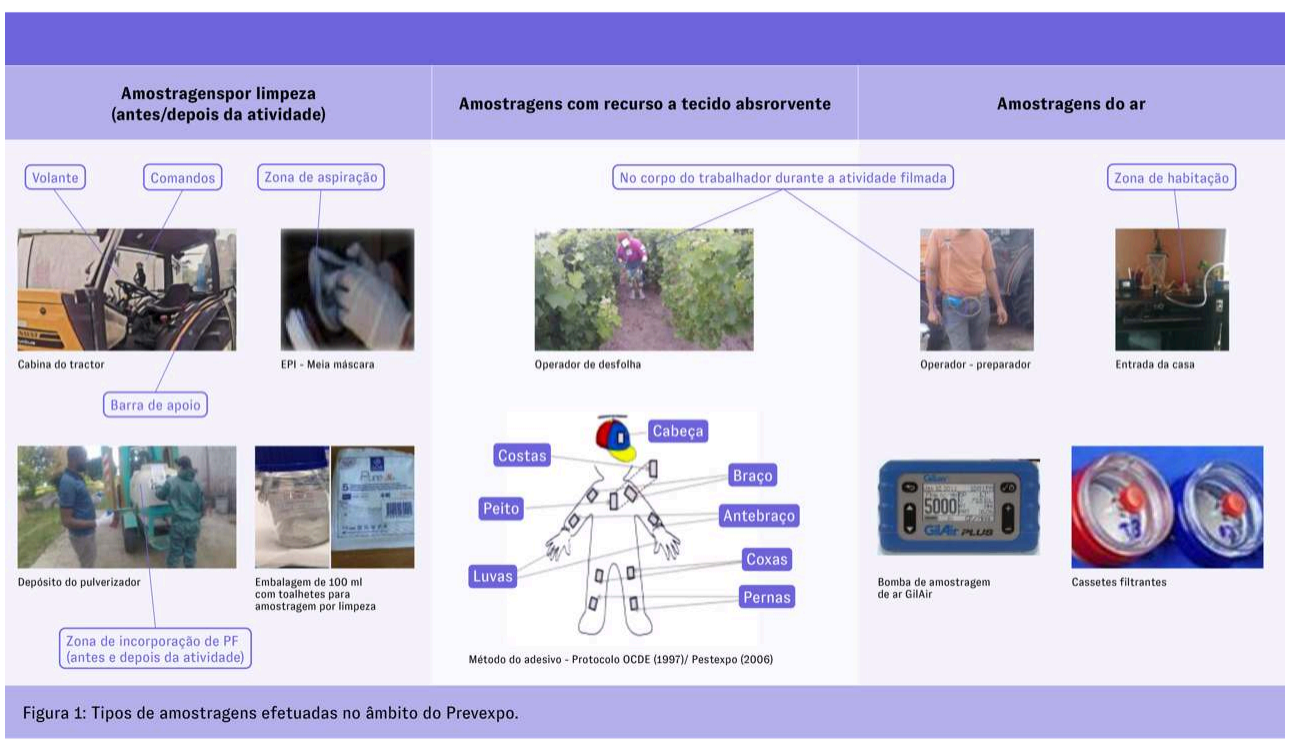

Figura 1 : Tipos de amostragens efetuadas no âmbito do Pravexpo

Em ergotoxicologia, as situações de trabalho de risco químico estão dependentes de uma série de condicionalismos: técnicos (tipo de substância, exigência do processo, material disponível, configuração arquitetónica, etc.); organizacionais (ritmo de trabalho, horários, exigências regulamentares); e humanos (formação, estatuto, 
experiência, etc.). 0 objetivo da intervenção é reverter o processo de produção dessas situações de risco químico transformando, através de ações técnicas, organizacionais e humanas, os determinantes dessas situações e criar, assim, "situações de prevenção" (Mohammed-Brahim, 2011).

Procurou-se, assim, prevenir situações de exposição a pesticidas averiguando quais os seus determinantes (composição da calda, material de preparação, arrumação do espaço fitossanitário, organização do trabalho, etc.), tentando, em seguida, transformálos. Para isso, realizaram-se várias ações de reflexão com os produtores: autoconfrontação, grupos de discussão e oficinas de simulação da atividade.

Efetuaram-se sessões de autocronfrontação com cada um dos produtores (com uma duração média de duas horas) a partir dos vídeos da atividade realizados entre maio e agosto de 2018. Os grupos de discussão (com uma duração de 1/2 dia) tiveram lugar, primeiro, entre junho e fevereiro de 2019, em cada uma das explorações com o proprietário e respetivo núcleo de intervenientes e, posteriormente em março e abril de 2019, com todos os proprietários. Estes grupos de discussão foram realizados utilizando os registos da atividade (imagens, planos, fichas dos dados de segurança, resultados metrológicos, etc.) (ver Figura 2).

Figura 2 : Imagens e resultados das observações instrumentais da atividade em sessões de autoconfrontação

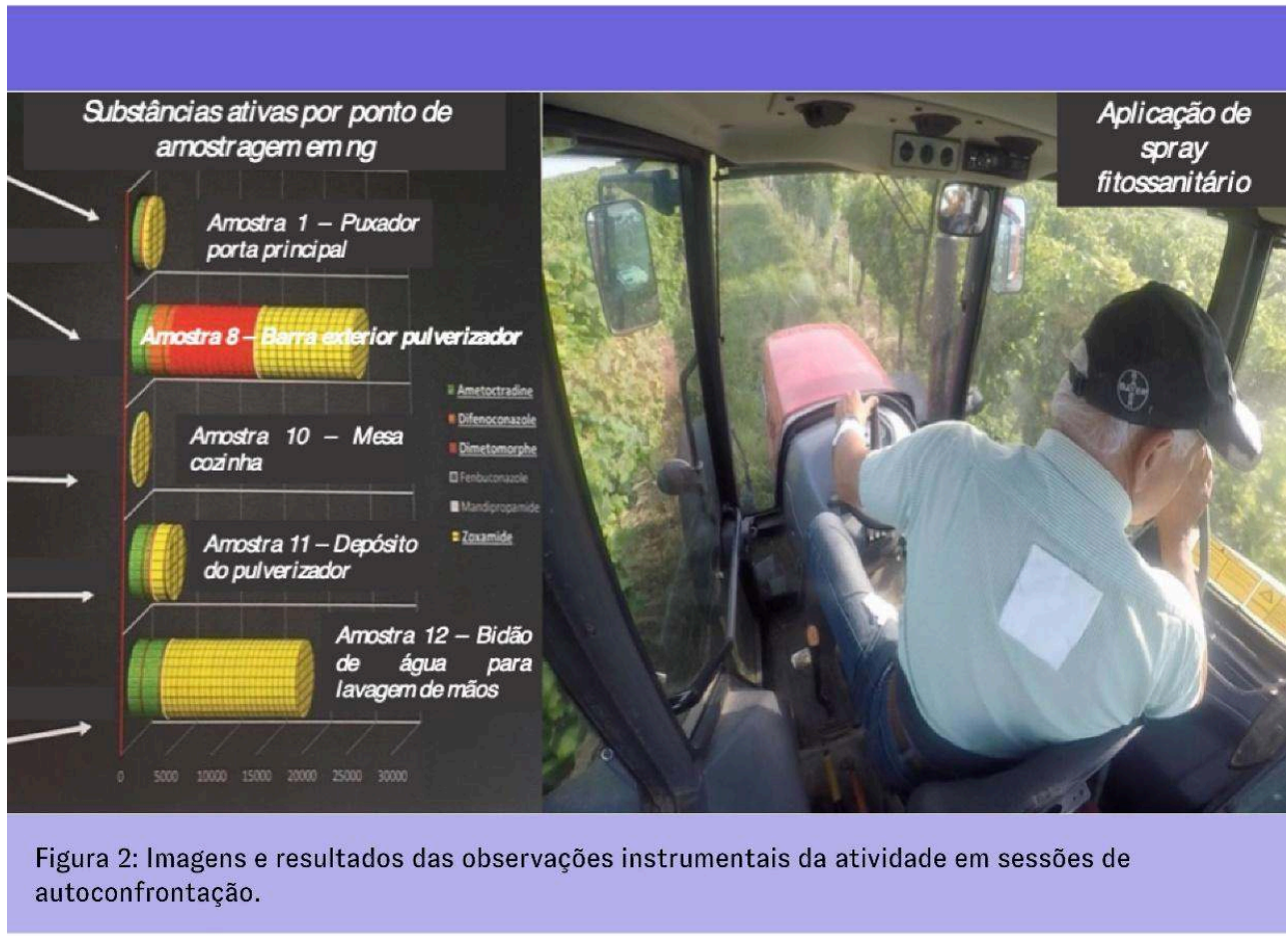

Figura 2 : Imagens e resultados das observações instrumentais da atividade em sessões de autoconfrontação

18 A oficina de simulação da atividade que reuniu ergonomistas e produtores (1/2 dia) examinou os constrangimentos (listados por um dos produtores), os modelos (construídos pela doutoranda) e documentos técnicos (encontrados na Internet). Foi a partir de tudo isto que, em conjunto, se estudaram as transformações (11 de abril de 2019). Os modelos, acompanhados de cartões com imagens, permitiram aos viticultores 
"explicarem a atividade" (Leplat, 2008) e verbalizarem as "situações críticas" encontradas para estudar a forma de as transformar (Caroly \& Weill-Fassina, 2004) (ver Figura 3). Com efeito, a partir dos modelos que representavam, em traços gerais, o dispositivo técnico, os viticultores puderam esclarecer os seus constrangimentos e recursos e discutir, entre si, os que cada um encontrava na operação de preparação da calda fitossanitária. Puderam contextualizar a sua atividade (estádio vegetativo da vinha, número de assalariados presentes, prazos, número e tipo de parcelas a tratar, tipo de produtos e equipamentos utilizados, etc.) e recolocar essa situação de trabalho no conjunto da sua atividade e, assim, identificar coletivamente os seus determinantes (meteorologia, atores, regulamentos, características dos produtos fitofarmacêuticos, etc.).

Figura 3 : Dispositivo técnico da exploração vitícola 1 em maqueta LEGO e imagens auxiliares que permitiram ilustrar a atividade

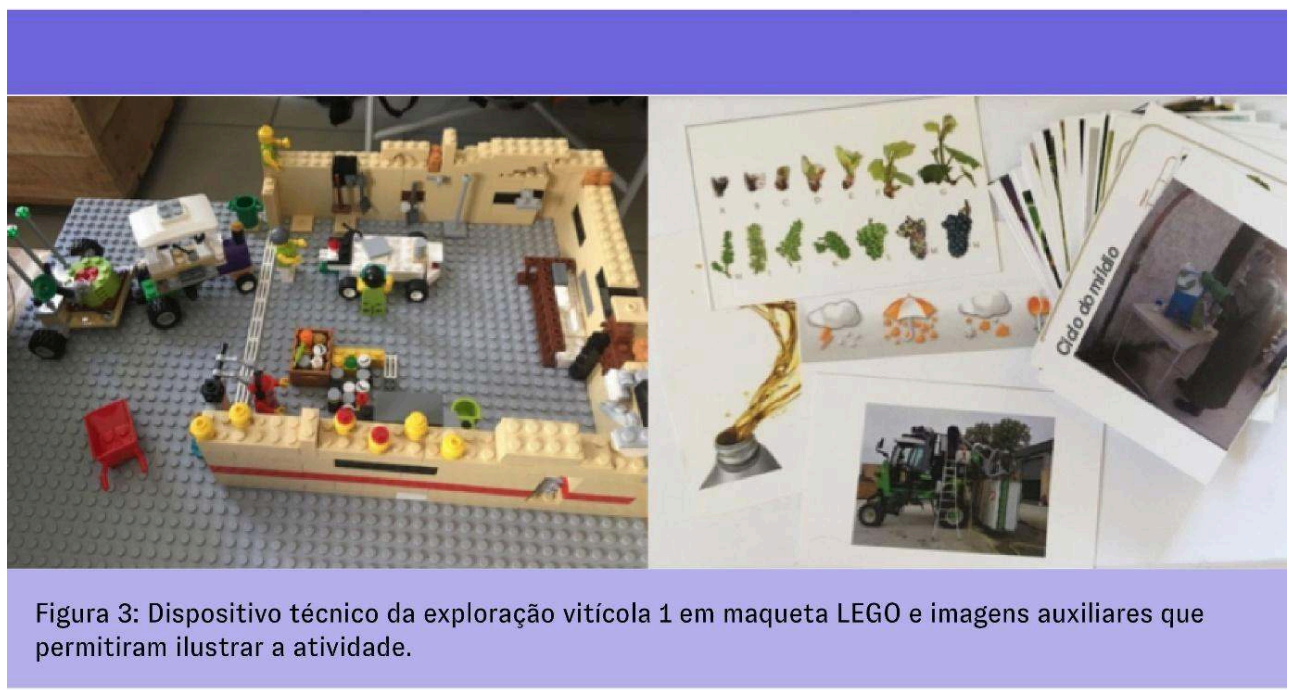

Figura 3 : Dispositivo técnico da exploração vitícola 1 em maqueta LEGO e imagens auxiliares que permitiram ilustrar a atividade

19 Na metodologia aplicada, o ergonomista foi um colaborador ativo. Propuseram-se apoios e instrumentos de modelização da realidade para "transmitir uma dinâmica coletiva" (Vinck, 2003) aos viticultores. Os "objetos intermediários" (ibid.) construídos ao longo do projeto, foram-se fazendo e refazendo graças aos viticultores que orquestraram a encenação da sua atividade.

A documentação das exposições aos pesticidas baseou-se nas dúvidas dos viticultores (por exemplo, a persistência dos pesticidas nos ambientes de trabalho ou a dispersão dos pesticidas para fora das áreas de preparação) e nas suas implicações (por exemplo, a imagem que os moradores da zona têm da empresa ou a preocupação de alguns clientes com os tratamentos). Os viticultores escolheram os pontos de amostragem dos pesticidas e, nalguns casos, foram eles próprios que realizaram as observações instrumentais nas suas explorações (depois de uma formação com os ergonomistas). Partindo da metrologia proposta pelos ergonomistas (tipos de amostragens possíveis, protocolo de amostragem em situações de trabalho, instrumentos de medição, conservação das amostras, coordenação com os laboratórios de análises, elaboração de tabelas e ilustração dos resultados), os viticultores conseguiram identificar as situações de risco dos pesticidas nos locais onde trabalham e nos locais onde vivem. 
21 Durante as reuniões coletivas e a oficina com os ergonomistas, analisaram-se, em conjunto (viticultores e ergonomistas), as condições que estão na origem de situações de risco dos pesticidas. A análise, através de uma abordagem horizontal ou partilhada, consistiu em determinar os constrangimentos sentidos pelos viticultores e as condições que favorecem o aparecimento de situações problemáticas no trabalho real. As simulações, reflexivas e construtivas (Bobillier Chaumon, Rouat, Laneyrie, \& Cuvillier, 2018), da atividade permitiram que a comunidade científica alargada concebesse, em conjunto, ações de prevenção. Nesse coletivo, assim constituído, os viticultores que utilizavam produtos fitofarmacêuticos tiveram a oportunidade, juntamente com os ergonomistas, de obter conhecimentos sobre a exposição real aos pesticidas que lhes vão servir para combater a dimensão nociva da sua atividade.

22 A observação da negociação e o questionamento das regras de prevenção pelos viticultores (em situações de trabalho e em espaços de diálogo) permitiu que se comprovasse a diferença que pode haver entre aquilo que está regulamentado ou prescrito e aquilo que acontece em condições reais de trabalho. $\mathrm{O}$ modelo de análise das várias dimensões da segurança regulamentada e controlada (Morel, Amalberti, \& Chauvin, 2008 ; Nascimento, Cuvelier, Mollo, Dicciocio, \& Falzon, 2013 ; Goutille et al., 2016) ajudou a compreender até que ponto o quadro regulatório e social da utilização dos produtos fitofarmacêuticos impede atualmente que os viticultores fomentem a segurança. Permitiu, ainda, analisar a forma como os vários atores contribuíram para a elaboração de regras de segurança em função do seu papel, estatuto, objetivos, constrangimentos, percursos e, em última análise, das representações do risco e do grau de proximidade de situações de exposição, e não diretamente em função do interesse dos viticultores.

23 A aplicação deste modelo às questões de saúde no trabalho também permitiu introduzir aspetos da gestão de riscos muitas vezes excluídos do modelo dominante de prevenção de riscos dos pesticidas e proporcionar uma conceção de práticas de prevenção eficazes à medida das situações de trabalho. A partir do encontro das várias dimensões da segurança, regulamentadas (elaboração de regras e dispositivos de segurança a partir da avaliação formal dos riscos identificáveis e previsíveis) e controladas (adaptação das regras prescritas e desenvolvimento de práticas de prevenção que sejam funcionais em ação), a reflexão sobre as situações de risco permitiu desenvolver novas soluções de prevenção baseadas em situações concretas de trabalho e de exposição debatidas nos espaços de discussão. A perspetiva de análise foi, assim, deslocada "de uma abordagem centrada nos fracassos e na identificação das causas de casos indesejáveis (acidentes, incidentes, erros, infrações, etc.) para uma compreensão mais alargada do agir em segurança" (Cuvelier \& Woods, 2019, p. 43) ou do agir em prevenção.

A partir de uma análise partilhada dos constrangimentos da atividade (na qual seria necessário atuar do ponto de vista dos operadores), os operadores e os ergonomistas puderam mobilizar os seus recursos pessoais e coletivos para conceber e realizar ações de transformação em diferentes escalas de tempo (objetivo imediato, a médio e a longo prazo). A ação conjunta procurou, assim, responder diretamente aos constrangimentos identificados pelos viticultores e permitiu também encontrar a forma de atuar a um nível mais alargado sobre os mecanismos e práticas sociais que regem a organização nacional e local da utilização de produtos fitofarmacêuticos no meio vitícola.

Por fim, ao interligar a dimensão individual e pessoal da atividade com a sua dimensão contextual e estrutural, as ações de prevenção a realizar puderam, assim, ser 
concebidas primeiro à escala da empresa e depois à escala do território de forma a permitir que os viticultores que utilizam produtos fitofarmacêuticos desenvolvam situações de prevenção.

\section{Resultados 1 : Exposições aos pesticidas em situações de trabalho e da vida dos viticultores}

O contacto dos viticultores com os pesticidas ocorre durante a manuseamento dos produtos fitofarmacêuticos (desarmazenagem, abertura, transvase, quantificação, transporte) e no conjunto dos procedimentos necessários à preparação da calda (pesagem e incorporação dos produtos, lavagem dos bidões, esvaziamento e limpeza do depósito, triagem e reciclagem das embalagens) (ver Figura 4). Esse contacto foi objeto de avaliação nos locais de tratamento (zonas de preparação e de aplicação da calda), nomeadamente, durante a preparação ou durante a manutenção do material e dos equipamentos. O grupo de produtores estava constantemente em contacto com parcelas contaminadas do material de tratamento e do ambiente de trabalho (paredes do tanque de mistura, bidões e sacos de produtos fitofarmacêuticos, instrumentos de pesagem, elementos das instalações como pavimento, instalações de água e eletricidade e puxadores das portas). Este contacto era causado pela necessidade de subirem à cuba ou de se apoiarem nela para recolha de dados (nível de enchimento, quantidade vertida, qualidade da mistura, funcionamento da agitação) ou terem acesso a algum equipamento (válvulas, manómetro, filtro, bomba) para controlarem o processo (evitar derramamentos e fugas, proteger o sistema de distribuição, controlar o aquecimento da bomba).

Os equipamentos e os espaços em que são manipulados e pulverizados os pesticidas são partilhados com outras pessoas, assalariados, membros da família, vizinhos, técnicos de manutenção do equipamento. Em virtude da persistência de certas substâncias ativas, o contacto acontece também em espaços não reservados à utilização dos produtos fitofarmacêuticos que podem disseminar-se para além das áreas de tratamento. Dentro da propriedade, as pessoas que nela trabalham (coatividade) ou circulam (assalariados, familiares, clientes, investigadores, técnicos, moradores), os seus objetos pessoais (viaturas, bolsas, vestuário) ou até mesmo os animais entram indiretamente em contacto com os pesticidas (ver Figura 4).

O empresário 1 afirmou ter a certeza de que o seu carro devia estar "mais poluído" do que a zona de preparação, porque "Muitas vezes pegamos em peças, trazemo-las para o carro, metemo-las na mala e pomos as mãos no volante" (E1, 11 de abril de 2019). Ele tinha-se dado conta de que os pesticidas podiam segui-lo até casa. Uma noite, em casa, a mulher deu-lhe um beijo e disse que ele "cheirava a pesticida até no pescoço", quando ele tinha acabado de tomar banho e, nesse dia, nem sequer tinha preparado nem feito nenhum tratamento (só tinha desmontado uma peça do pulverizador) (E1, 11 de abril de 2019).

Uma assalariada da empresa 1 que trabalha na vinha diz sentir-se, por vezes, tão "cercada pelos tratamentos" que até lhe apetecia pedir uma máscara (assalariada 2, 17 de maio de 2018). Diz "sentir, sobretudo, os cheiros do vizinho" que, do outro lado do caminho, "trabalha à moda antiga", sem recuperador nem cabina (ibid.). 
Figura 4 : Presença, contacto e dispersão ddos pesticidas entre atividades e espaços de trabalho e de habitação (pesticidas a vermelho e EPI a azul). Desenho de Alexandra Belle, 2021

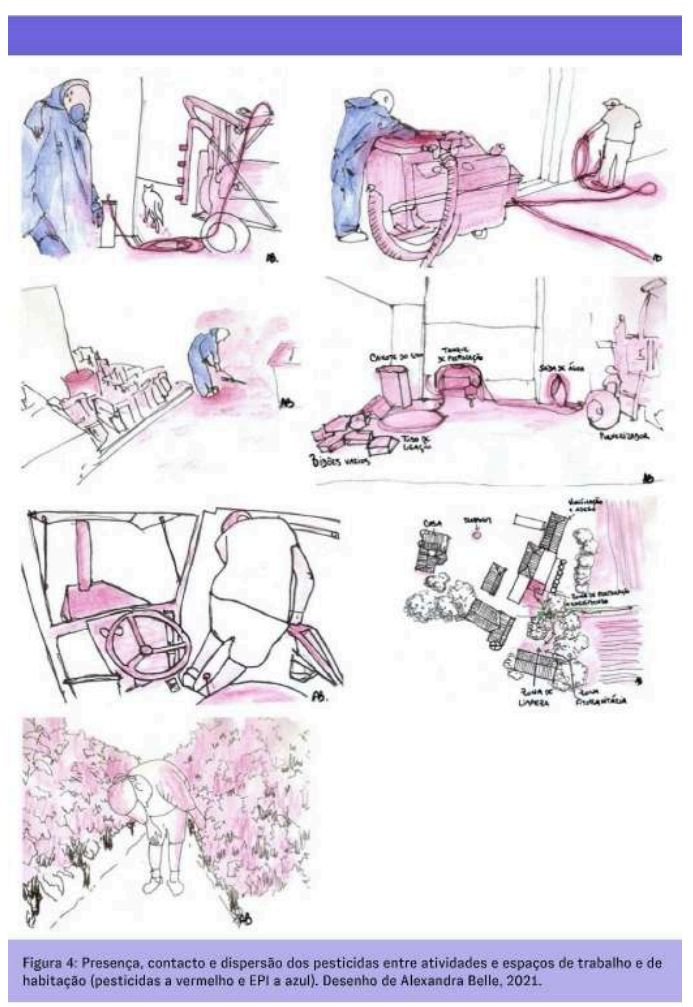

Figura 4 : Presença, contacto e dispersão ddos pesticidas entre atividades e espaços de trabalho e de habitação (pesticidas a vermelho e EPI a azul). Desenho de Alexandra Belle, 2021

A análise desenvolvida no âmbito do Prevexpo permitiu incluir o risco dos pesticidas em toda a atividade do viticultor e dar visibilidade a um risco dos pesticidas pouco controlável a nível da exploração vitícola e até mesmo do território. Os resultados obtidos mostram que o contacto pode acontecer na própria empresa (escritórios, receção, espaços de restauração, carro de serviço), na propriedade (puxadores das portas, mesas e janelas da casa ou do jardim, roupas e pele do viticultor), mas também a nível do território (família, vizinhos, fileira de reciclagem dos efluentes, concessionários).

\section{Resultados 2 : uma construção territorial da atividade de tratamento que impede os viticultores de criarem situações de prevenção}

31 Nos últimos anos, o território francês viu nascer uma forte mobilização de militantes contra os pesticidas agrícolas :

- Marchas brancas em Paris, em Bordéus (ver Figura 5), ou da Cruz Branca na região do Médoc, no meio das vinhas, reúnem moradores, familiares de vítimas, sindicatos e militantes anti-pesticidas. 
Figura 5 : Operação Marcha Branca organizada pelo Collectif Info Médoc Pesticides, 14 de fevereiro, 2016. Bordéus. Pode ler-se nos cartazes: “Pesticidas crime contra a vida de todos » e “Pesticidas pulverizados, crianças expostas, saúde ameaçada ! Basta »

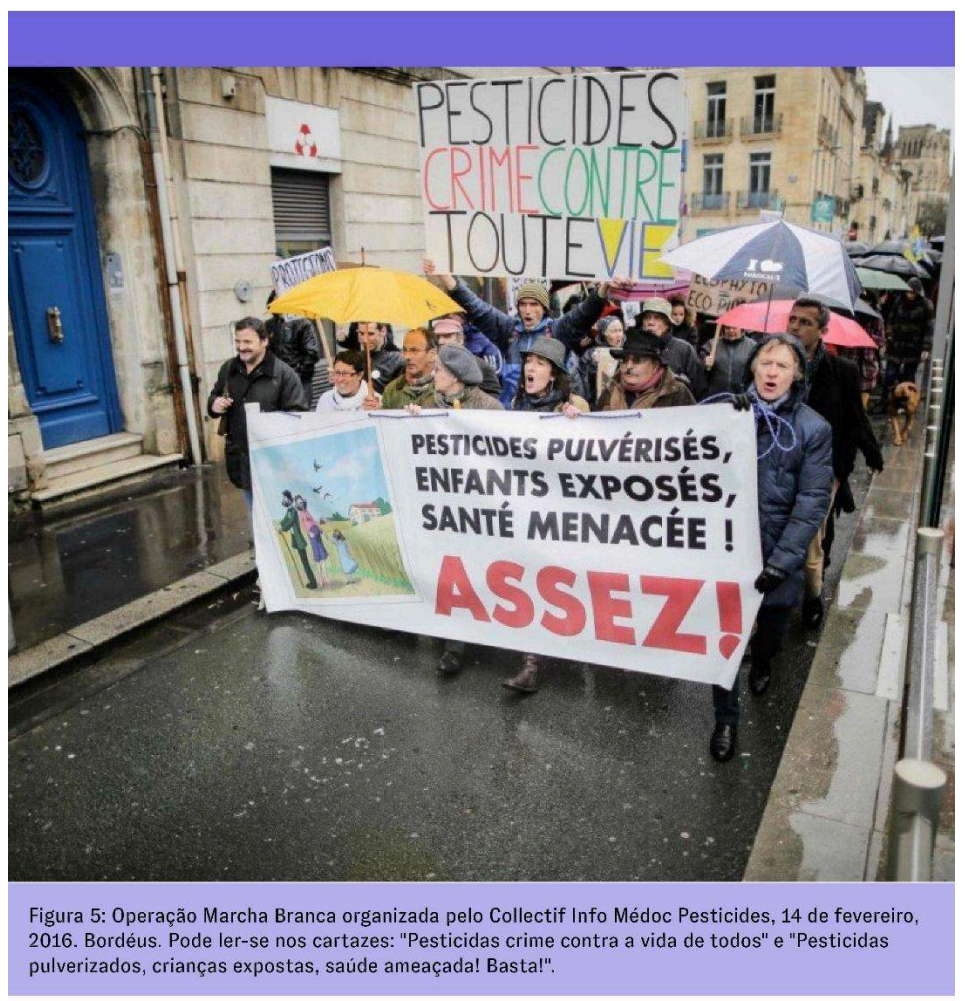

Figura 5 : Operação Marcha Branca organizada pelo Collectif Info Médoc Pesticides, 14 de fevereiro, 2016. Bordéus. Pode ler-se nos cartazes : "Pesticidas crime contra a vida de todos » e "Pesticidas pulverizados, crianças expostas, saúde ameaçada! Basta »

- Associações que organizam recolhas de amostras de pesticida em garrafas de vinho de Bordéus e na água, nos terrenos próximos de parcelas tratadas, bem como no cabelo e na urina dos vizinhos dos agricultores.

- Mediatização das denúncias de viticultores que desrespeitarem a legislação.

- Documentários televisivos que acumulam provas de uma agricultura poluente. Um vasto conjunto de situações que causa divisão entre os agricultores (e também entre as suas instâncias representativas).

- Situações em que os viticultores são estigmatizados por diferentes sectores da sociedade civil que tomam posição a favor de determinado tipo de agricultura em detrimento de outro (mecanizada, manual, industrial, agroquímica, biológica, etc.).

- Ações da sociedade civil que forçam as autoridades a exercerem um controlo cada vez mais apertado do uso de produtos fitofarmacêuticos.

Neste contexto, constatou-se que não é fácil para os viticultores virem a público falar das exposições aos "químicos", lançar a dúvida sobre o potencial tóxico dos produtos fitofarmacêuticos (uso e eficácia, proveniência e proteção ambiental, dispersão e saúde, etc.), manifestar receios em relação à sua saúde ou à dos que os rodeiam. Falar disso pode "prejudicar a profissão" confiou um dos interlocutores abordados. Chamar a atenção para as exposições aos pesticidas "é muito interessante", mas pode "dar novas armas àqueles que nos acusam" (sócio-gerente 2, E2, 28 de junho de 2018) ou contribuir para atacar uma profissão já sob a mira dos media e sujeita à pressão social, sobretudo na Gironda. Num contexto que "diz respeito a todos", para evitar "focos de tensão", há 
que "pensar na forma como abordamos o assunto" dos pesticidas diz a sócia-gerente 1 (da exploração 5) :

"Este fim-de-semana, ouvi alguém de fora dizer: 'Vimos um fulano que andava a tratar a vinha com os filhos à volta. Anda a sulfatar os filhos.' $\mathrm{E}$ eu pergunto como é que ele continua na mesma. E do outro lado há indivíduos de fora (investigadores? pessoal da prevenção? representantes dos sindicatos agrícolas ?) que trazem já ideias bem definidas sobre os riscos. E nós o que é que havemos de fazer? Não podemos criar... se falamos de determinados assuntos, não quero criar problemas. Para já, é melhor não alarmar os assalariados. Porque é verdade que os há, aqueles que já fazem prevenção. Porque já fazemos prevenção. Mas ao pé deles há práticas sem qualquer tipo de prevenção. E é verdade que isso gera tensões e diferenças nas práticas dentro de um mesmo território. Não é fácil, mas eu vou com calma, porque isto pode ser fonte de tensões e, se não pensarmos bem no modo como abordamos o assunto, eles vão encher os ouvidos dos outros. 0 que acontece é que eles têm contacto com assalariados de outras empresas. E, depois, os empregadores também podem virar-se um bocado contra o nosso trabalho (de prevenção?) por termos andado depressa de mais e também sem avisar os nossos colegas. Há um trabalho de relacionamento que tem de ser feito. Porque, de facto, as práticas e a vizinhança dentro da profissão e a vizinhança à volta dela também nos preocupam na Gironda. Lá está, a verdade é que eu sou responsável profissional e nós trabalhamos todos esses temas tendo em conta a relação com a vizinhança, e depois normalmente utilizamos meios quando fazemos tratamento perto das casas, como enviar mensagens sms [...], porque nós temos práticas hiper... Enfim, muito precisas com equipamento eficiente, mas o meu vizinho de trás... São as vinhas mesmo atrás da casa e, é claro, sem proteção nenhuma, e então aí eu fecho as janelas [...] Estamos a pisar um terreno desconhecido para nós [...] Eu acho que não estamos suficientemente preparados, e, depois, a verdade é que na Gironda nós somos profissionalmente frágeis nesse aspeto, por isso, é preciso ter muito cuidado" (sócia-gerente 1, E5, 27 de Junho de 2018).

Durante o projeto, verificou-se que a dimensão produtiva da atividade de trabalho (dirigida para a produção de bens e serviços) podia contribuir para que os profissionais construíssem e mantivessem uma representação longínqua do risco dos pesticidas. Embora os esforços para a securitização das pessoas no trabalho sejam notáveis [4] (sobretudo ao nível das empresas que contratam assalariados - E0, E1, E4), na prática, são sobretudo as questões de produtividade que levam a melhor sobre a segurança pessoal, principalmente ao nível dos empresários vitícolas. Graças à inclusão, nesta análise [5], da dimensão contextual da atividade de tratamento, foi possível compreender por que motivo, para os empresários vitícolas, o risco dos pesticidas não podia ser uma prioridade no meio de todos os constrangimentos económicos, agronómicos, sociais e jurídicos da referida atividade. Ante o perigo dos pesticidas, os responsáveis pelas explorações vitícolas sentiam-se ameaçados pela pressão societal sobre a profissão e pelas regulamentações da utilização dos produtos fitofarmacêuticos. Convém esclarecer que eles tinham acompanhado os processos contra alguns viticultores da região de Bordéus e tinham podido observar de perto as consequências das novas regulamentações sobre a sua atividade de tratamento. Os resultados da investigação mostram que o distanciamento sentido pelos agricultores relativamente ao risco dos pesticidas é reforçado pelo contexto territorial da sua atividade, ou seja, pelo quadro regulamentar, profissional, económico e social em que 
se realiza a sua atividade de tratamento. Foi possível constatar que o meio profissional vitícola em que se realiza a atividade dos empresários vitícolas pode ser comandado por importantes questões de ordem financeira (PIB francês, mercado do vinho, Política Agrícola Comum) que contribuem para manter a utilização dos produtos fitofarmacêuticos e defender uma resposta agroquímica para os problemas agrícolas [ ${ }^{6}$. Segue-se a apresentação de alguns exemplos que mostram como essas questões inscritas num contexto nacional de "utilização controlada dos pesticidas" (Jouzel, 2019) constituem entraves à construção da prevenção do risco dos pesticidas.

Perante as ameaças que "pesam sobre a profissão" (processos contra os viticultores da região de Bordéus, aumento das regulamentações relativas à utilização dos produtos fitofarmacêuticos, pressão societal), as organizações profissionais que reúnem localmente os empresários e que atuam no território da produção vitícola (por exemplo, Conselho Interprofissional dos Vinhos de Bordéus e cooperativas vinícolas) procuram salientar os esforços da profissão em prol do ambiente. Estas organizações assumiam compromissos sociais (aviso à vizinhança antes da fertilização, atualização dos cadernos de campo para as denominações "Bordeaux", retirada das substâncias classificadas CMR, isto é, cancerígenas, mutagénicas e tóxicas para a reprodução, etc.), sem, no entanto, visarem a aplicação de medidas de prevenção concretas (para proteger os utilizadores de produtos fitofarmacêuticos da exposição aos pesticidas).

Veja-se um exemplo de medidas de prevenção com vista à redução do risco dos pesticidas com a retirada das substâncias CMR dos programas de tratamento. A promoção da maior parte dos produtos fitofarmacêuticos é feita com base no destaque da sua eficácia agronómica. E, para melhorar o desempenho destes produtos (conservação, aplicação e persistência nas culturas), propõe-se a utilização de adjuvantes. De facto, nenhuma das fichas técnicas que acompanham os produtos de tratamento estudados no projeto refere propriedades que visem a segurança do utilizador. 0 marketing praticado pelas empresas centra-se nos resultados do produto nas culturas, e pouco nas possibilidades de proteção individual durante a sua utilização. A estratégia dos conselheiros vitícolas locais para venda e colocação no mercado dos produtos nem sempre está, ou melhor, nunca está orientada para a proteção das pessoas. Ela tem vindo a adaptar-se à evolução do mercado do vinho e, atualmente, fálo através da promoção de produtos fitofarmacêuticos não CMR que permitem a certificação de um modo de produção com valor ambiental elevado. Desse modo, na atividade propriamente dita, os membros do conselho propõem aos empresários vitícolas programas de tratamento que incluem dezenas de substâncias ativas que, embora por vezes sejam não $\mathrm{CMR}$, não deixam de ter efeitos graves e irreversíveis para a saúde. Perante as pressões sociais para uma redução da utilização dos produtos CMR, os produtos divulgados e comercializados são cada vez menos CMR, ou seja, não são classificados como tais, mas continuam a ser potencialmente muito tóxicos para o utilizador e para o ambiente.

Veja-se um outro exemplo sobre a influência do Conselho Interprofissional do Vinho de Bordéus (CIVB) nas práticas dos empresários vitícolas contactados. O CIVB é um dos principais atores que participam na organização da produção do vinho com utilização controlada dos produtos fitofarmacêuticos no território das denominações de vinhos de Bordéus [7]. Para "reforçar a marca", corresponder "à análise dos mercados" e adaptar a produção às previsões de comercialização, a organização interprofissional dedicou-se, em 2018, "à inclusão de medidas agroambientais nos cadernos de campo das DOC 
[denominações de origem controlada] de Bordéus". No guia de orientação para os profissionais (2018-2025), a CIVB propõe uma evolução das práticas de tratamento no que respeita a equipamentos (bicos anti-escorrimento, contenção), à preparação da vinha (plantação de sebes, redes, arranque, etc.) e à organização de trabalho (supressão de determinados produtos, elaboração do calendário e reflexões participativas). Neste sentido, o CIVB incentiva as empresas a obterem o selo de Valor Ambiental Elevado, uma certificação baseada em regras ambientais e na avaliação de indicadores de desempenho que não proíbe a produção de vinho com recurso a pesticidas, mas que recomenda uma produção, por assim dizer, "mais verde", "precisa" e "controlável" em todo o território francês. Os empresários vitícolas passam, assim, a poder exibir o selo nas garrafas do seu vinho e a valorizar as práticas de trabalho orientadas para a agroecologia. Os esforços para se adaptarem a essas normas e criarem biodiversidade (sebes e colmeias) foram estimulados e recompensados com um apoio financeiro, no presente (crédito fiscal de 2500 euros) e no futuro (subsídios previstos na PAC 2023).

38 E um último exemplo, desta vez, sobre a agricultura de precisão (otimização da produção com recurso às novas tecnologias) e as suas vicissitudes no que toca à prevenção do risco dos pesticidas. Na Nova Aquitânia, o programa regional de investimento público-privado VitiREV, dotado com um orçamento considerável (€ $73600000 \mathrm{em} 10$ anos), foi lançado em 2019 com o objetivo expresso de "dar um novo passo para a eliminação dos pesticidas na viticultura". O objetivo central deste programa é a promoção da agricultura de precisão, recusando propostas de modelos de produção alternativos e a possibilidade da colaboração de pessoas do ramo na definição das inovações que dizem respeito à sua profissão (só os sindicatos podem colaborar nesse programa ao lado dos técnicos, engenheiros e investigadores). Também nessa mesma linha, há um programa de mais de vinte milhões de euros para a conceção do pulverizador do futuro que não aceita a participação direta dos viticultores independentes. $\mathrm{O}$ concurso está apenas aberto a instituições de investigação privadas e públicas reconhecidas, tal como denuncia um dos viticultores do Prevexpo (E1, 11 de abril de 2019).

O pulverizador da exploração vitícola 5, comercializado como mais-valia ambiental, foi concebido para permitir que os viticultores reduzissem as áreas de não tratamento. Graças aos painéis de recuperação e aos bicos orientáveis, a calda fitossanitária pode ser aplicada a 5 metros em vez de a 20,50 ou 100 metros [ $\left.{ }^{8}\right]$ das casas e de outras construções vizinhas. Esta inovação tecnológica que, em princípio, tenta responder aos desafios ambientais, agronómicos e económicos, dificulta significativamente o desempenho dessa atividade. Perante inovações deste tipo, desligadas do contexto de utilização, os profissionais acabam por ter de resolver problemas de conceção dos equipamentos agrícolas à mistura com questões de ordem económica e ambiental que não podem controlar :

- (E5, sócia-gerente 1) : De facto, as avarias é que nos penalizam, a duração das avarias, e que nos fazem atrasar todo o resto.

- (E5, sócio-gerente 2) : De facto, o tempo de lavagem é maior (em relação ao material antigo) e, afinal, passa-se mais tempo a lavar...[...] As avarias[...] Os bicos [...]Pode ser a filtragem entupida [...] É preciso limpar os filtros [...] Eu lavo-os todos os dias, mas é um aparelho que não é mau, mas que ainda não é perfeito e, pronto, eu não percebo como é que se vendem aparelhos que ainda não são perfeitos... 


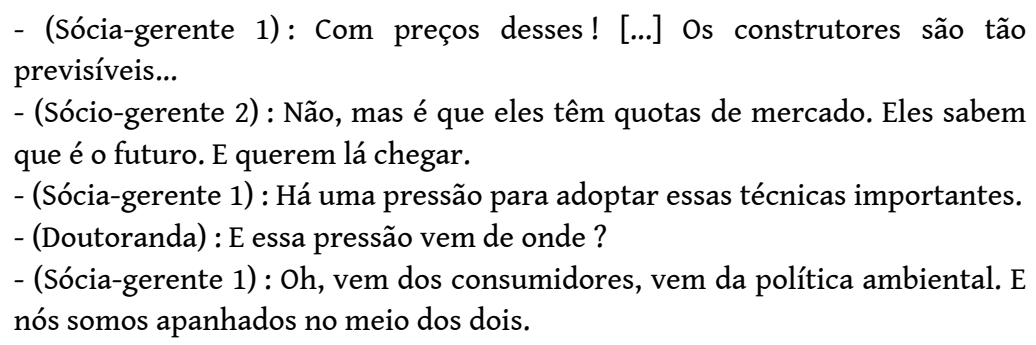

40 Adquirir esse tipo de material, sobretudo se for de última geração, obriga os profissionais a operar dentro de uma cabina, com dados e painéis digitais que os afastam cada vez mais da terra e os levam a endividar-se para, no fim de contas, muitas vezes serem eles quem "paga as favas por causa do material ainda não devidamente testado" (sócia-gerente 1, E5, 27 juin 2018). Durante a observação filmada em 8 de Maio de 2018, o empresário vitícola 5, por exemplo, referiu um problema de material que tinha tido na véspera. As suas declarações permitem ilustrar um problema de conceção voltada para a preservação do ambiente em detrimento da preservação do indivíduo em atividade : "Para começar, já estou furioso. Ontem, houve um bico que entupiu e eu levei duas horas, em vez de uma hora e vinte, a fazer a fertilização. Recebi uns quantos telefonemas, mas levei duas horas! [...] Eu estava a fazer uma média de 7,2 $\mathrm{km}$ por hora [...] Tive um problema com o bico [...] Era do sistema de filtragem. Há uma bomba que faz a mistura (do produto) [...] Foi preciso filtrar as impurezas, porque elas entopem os bicos. Não deixar que o produto passe para fora da vinha e respeitar os 5 metros da área de não-tratamento é claro que faz parte do progresso, mas será que uma calda espessa consegue passar por um buraquinho ? Portanto, é um benefício para o ambiente, mas não para a pessoa que faz o tratamento. E eu? Quantas vezes é que estou em contacto com os bicos!?" (sócio-gerente 2, 8 de maio de 2018).

41 Ter problemas com os filtros implica não só uma perda de tempo para os empresários vitícolas, mas implica também esforços suplementares e descer do trator em pleno tratamento :

- (sócio-gerente 2, 27 de junho de 2018) : Eu vou-lhe passar o volante e você vai ver, vai perceber logo, num quarto de hora vai perceber. Ele é subir, é descer, é desatarraxar o bico e desentupi-lo, subir, voltar a subir para o trator, pôr tudo em andamento, toca a andar, fazem-se 100 metros e...bolas, entupiu do outro lado! Paramos, descemos, tiramos o bico, pomos luvas, claro. E a máscara, nem lhe digo, não tenho tempo para a pôr. É preciso limpar e voltar a subir. Arrancamos outra vez e, cinco minutos depois, lá está mais um (bico), mais dois, e às vezes é aos pares, aos três e aos quatro...

- (sócia-gerente 1) : A verdade é que os tratamentos têm mesmo de se fazer

- (sócio-gerente 2) : E o tempo vai passando

- (sócia-gerente 1) : E os dias passam

- (sócio-gerente 2) : Porque no célebre dia em que eu estava furioso, parei ao fim da tarde e ainda me faltava fazer dois hectares e meio. Achava eu que ia fazê-los à noite...

- (sócia-gerente 1) : Mas o que acontece é que, depois, fica tudo desfasado - (sócio-gerente 2) : E, depois, no dia seguinte, o tempo tem de estar bom, não pode chover

- (sócia-gerente 1) : Fica tudo alterado e atrasa-se tudo

- (sócio-gerente 2) : No dia seguinte, ia estar bom e, por isso, eu parei, porque estava irritado. Foram pr'aí uns 2 litros de água, posso-lhe garantir 
- (Doutoranda) : Então, isso quer dizer que esses problemas de conceção podem levar a perdas de tempo para a sua atividade e à sua própria exposição...

- (sócio-gerente 2) : Pois, lá está..., é que a gente desce, a porta do trator acaba por ficar aberta, estou farto de abrir e fechar. Portanto, ora estamos na máquina, ora no túnel, tiramos os bicos, vamos lavá-los com água e, a seguir, tornamos a subir, lavamos as mãos e arrancamos.

42 Este tipo de problemas e de falhas dos fabricantes, dos revendedores de equipamentos ou dos concessionários que operam no território do viticultor é sobretudo o resultado de uma tentativa de dar resposta à regulamentação e não à atividade de trabalho em causa. Os empresários vitícolas associam estes problemas a uma comercialização demasiado prematura dos aparelhos de tratamento que não tiveram tempo de ser testados em funcionamento. Acontece, assim, que os utilizadores que investiram em equipamentos modernos, em princípio eficientes, passam à situação de operadores de testes. Chegam a adaptar eles próprios os equipamentos ou a entregar as alterações técnicas aos concessionários em quem confiam no caso de estarem estabelecidos no seu território.

Concluindo, os empresários vitícolas, para realizarem os tratamentos fitossanitários, têm de se adaptar aos equipamentos comercializados para esses tratamentos (produtos fitofarmacêuticos, tanques de incorporação, pulverizadores, EPI). Têm de adaptar as práticas de trabalho ao formato dos produtos (altura, largura, afastamento e proximidade dos diferentes componentes), à capacidade de cada um (em termos de volume, agitação, lavagem, pulverização, recuperação, permeação), às evoluçães tecnológicas (novos bicos de pulverização, nova sonda, novo sistema de lavagem, novo painel de bordo, EPI mais confortáveis) ou às (in)compatibilidades com o trabalho real e com outros equipamentos da exploração (trator, zona de preparação, local fitossanitário, compasso de plantação, etc.). Assim, no contexto duma utilização controlada de pesticidas, os viticultores acabam por ser alvo de múltiplas disposições técnicas e regulamentares que regem a profissão, mas que não os ajudam a protegeremse da exposição aos pesticidas.

As adegas cooperativas, os fornecedores agrícolas, a Câmara da Agricultura, o Conselho Interprofissional do Vinho e, mais indiretamente, a Mutualidade Social Agrícola (MSA), o Instituto Nacional de Investigação Agrícola, Alimentar e Ambiental (INRAE) ou o Instituto Nacional da Saúde e da Investigação Médica (INSERM) são todos atores envolvidos nas práticas vitícolas e cada um contribui, à sua maneira, com uma estratégia estrutural, uma ligação à "transição agroecológica" (Candau, Ginelli, Garrigou, \& Goutille, 2021) que, no fundo, significa mostrar aos profissionais qual ou quais produtos (substâncias, materiais, equipamentos, etc.) melhor se adaptam às suas necessidades (económicas, técnicas, tecnológicas, agronómicas, regulamentares, éticas ou sanitárias). Alguns destes actores sugerem-lhes compras em grupo para reduzirem os custos. Outros elogiam as características de novos produtos adaptados às evoluções do mercado do vinho. Outros, ainda, alertam-nos para os efeitos que os produtos fitofarmacêuticos de síntese química podem ter sobre a saúde. E assim por diante... Nesta competição de atores, algumas empresas fitofarmacêuticas conseguem apresentar argumentos que combinam várias destas estratégias para se imporem como referência prioritária junto dos empresários vitícolas ou dos seus conselheiros no que diz respeito à atividade de tratamento. 

adaptação às pressões territoriais locais e nacionais. Procuram evitar conflitos com os moradores e os novos rurais, ao mesmo tempo que tentam respeitar as normas ambientais e as recomendações de tratamento emitidas pelos organismos profissionais locais. Para reduzirem o risco de ações judiciais, os viticultores vêem-se obrigados a flexibilizar as suas atividades (por exemplo, fazer os tratamentos à noite ou depois de as escolas fecharem) e a aplicar, constantemente, novas e cada vez mais numerosas medidas regulamentares. Chegam ao ponto de terem de seguir e aplicar regras pouco eficazes para minimizar o conflito, mesmo com a família, nomeadamente quando os mais próximos, às vezes o cônjuge, os interrogam sobre a necessidade de se protegerem. Os viticultores contactados vêem-se, por exemplo, forçados a usar EPI pouco adequados à sua atividade e de obrigar outros a usá-los, mesmo reconhecendo que são ineficazes. Na prática, chegam a esconder-se das pessoas com quem convivem (família, outros funcionários, coordenadores, vizinhos), umas vezes porque estão sem EPI durante uma operação de tratamento, outras vezes por os EPI darem muito nas vistas e lançarem a suspeita, ou melhor, denunciarem a realização de uma prática tóxica (Nicourt, 2016) pondo em sobressalto os moradores de áreas de tratamento habitadas.

\section{Resultados 3 : qual o contributo da investigação- intervenção para a prevenção do risco dos pesticidas?}

A investigação-intervenção, na sua dimensão ergotoxicológica, centrou-se na operação de preparação da calda fitossanitária. Essa operação foi filmada em todas as empresas e a atividade da pessoa encarregada dessa operação foi posteriormente analisada. 0 principal objetivo era compreender as situações de risco dos pesticidas e respetivos determinantes. Com base num modelo aperfeiçoado de intervenção em ergotoxicologia, foi possível analisar a atividade de trabalho e as situações de risco dos pesticidas a dois níveis distintos : no ato de preparação e no contexto territorial da sua realização.

A análise da atividade no ato de preparação permitiu documentar exposições reais que os atuais instrumentos de avaliação de risco dos pesticidas não conseguem. Foi essa análise que facilitou uma melhor compreensão das condições (determinantes técnicos, organizacionais e humanos) em que ocorrem essas exposições aos pesticidas durante a preparação da calda. Este nível de análise permitiu que se observasse a forma como as pessoas que intervinham nessa operação conseguiam ou não utilizar o corpo e a mente para responder aos imprevistos e às exigências da preparação da calda. Permitiu igualmente revelar de que modo os preparadores adaptavam as regras de segurança (por exemplo, não usar máscara de proteção), criavam estratégias para conseguir gerir diferentes situações (relativamente às substâncias e equipamentos utilizados, às exigências físicas ou cognitivas, aos constrangimentos cinestésicos, etc.) ou encontravam soluções de compromisso para respeitar conjuntamente vários objetivos (por exemplo, qualidade, segurança e eficácia).

48 A análise da atividade no seu contexto de realização permitiu estabelecer os macrodeterminantes da atividade de tratamento que a análise da atividade no ato de preparação não tinha como objetivo direto incluir. Por outras palavras, a análise dos

Laboreal, Volume 17 №2 | 2021 
constrangimentos do trabalho permitiu uma melhor compreensão dos constrangimentos no trabalho criados à escala territorial e das normas sociais e culturais. Tratou-se, assim, de uma "análise mais alargada da atividade" (Bellemare, Montreuil, Marier, Prévost, \& Allard, 2001) do que aquela que é tradicionalmente seguida pela ergotoxicologia. A dimensão contextual da atividade foi incluída para se entenderem as implicações políticas, sociais e económicas que condicionam as dimensões organizacionais e produtivas da utilização de produtos fitofarmacêuticos.

Relacionar os dois níveis de análise permitiu não só obter dados sobre as exposições e respetivas condições de produção, mas também procurar a forma de as transformar no ponto em que se geram (origem) e antes de ocorrerem (resultado). Depois de se ter reconhecido, em conjunto com os viticultores, que a utilização controlada de pesticidas constituía um obstáculo à atividade de tratamento (por exemplo, a promoção e a comercialização dos produtos fitossanitários tais como os materiais ou os equipamentos de tratamento) foi possível encontrar os atores que tinham que ver com esse obstáculo : os que sofrem as consequências (por exemplo, os viticultores) e também aqueles cuja ligação é mais longínqua (por exemplo, fabricantes e moradores). Foi possível refletir, em conjunto com os atores, sobre as implicações e representações de cada um relativamente ao problema que apresentavam. $O$ contexto de cada um desses atores foi tido em conta, tal como o contexto territorial (socioeconómico, cultural, etc.) relativamente ao seu impacto no obstáculo referido. Esta investigação conjunta permitiu compreender melhor o sistema a que os operadores estavam submetidos. Permitiu ainda um enriquecimento mútuo pelo simples facto de abrir o campo de análise e incluir atores (e fatores) inicialmente não abrangidos. Permitiu ainda compreender que a origem das exposições aos pesticidas decorrentes de um nível mais estrutural (território local e nacional) devia ser tida em conta para que os utilizadores de produtos fitofarmacêuticos deixassem de se sentir como os únicos responsáveis pelas exposições.

Esta secção vai mostrar como a investigação-intervenção efetuada, que permitiu transformações ao nível das empresas envolvidas, merece ser continuada para iniciar uma ação ergonómica ao nível do território.

51 Entre as pessoas contactadas durante o projeto [?], algumas tinham conhecimentos muito precisos sobre o perigo e os mecanismos de ação dos pesticidas. As pessoas que tinham sido vítimas de pesticidas (vítimas declaradas ou não), testemunhas ou próximas de alguma vítima, estavam ansiosas por perceber a relação entre perigo e exposição. Relacionar o sintoma $\left.{ }^{10}\right]$ com a causa, apesar de não haver uma prova formal, levou a grande maioria a considerar que os pesticidas eram um problema a combater. A partir dessa constatação, começaram a envolver-se de diferentes formas no combate aos pesticidas (contestação das condições de exposição, processos judiciais contra empresas ou instituições, pedidos de reconhecimento de doença profissional, lutas sindicais ou criação de uma rede de luta contra os pesticidas).

Depois de materializar o perigo, de atribuir uma cara ou uma imagem aterradora ao perigo, essas pessoas, algumas das quais utilizadoras de produtos fitofarmacêuticos, desenvolveram uma reação negativa relativamente aos pesticidas. A "implantação" e a "objectivação" do perigo (Moscovici, 2000), por considerarem que certos casos eram idênticos, levaram essas pessoas a verem nos pesticidas um elemento produtor de risco, pondo-as de sobreaviso quanto à sua capacidade destrutiva. 

que depois de ter visto as crianças "lá do sítio" vítimas de leucemia, punha em causa o seu trabalho. No serviço do hospital onde a mulher dele trabalhava, as doenças que alguns associavam aos "químicos" ou os cancros que "se apanhavam" nas vinhas, para ele tinham um rosto. As imagens das caras das crianças e dos seus corpos enfraquecidos ficaram-lhe gravadas na memória. Desde então, procurava respostas que pudessem ajudá-lo a resolver os conflitos de objetivos que ele sentia entre a vida profissional e a vida pessoal. Ou ainda o testemunho da sócia-gerente 1 (empresa 5) que reconhecia nos seus pais as patologias descritas em estudos científicos :

"Eu os primeiros tratamentos que fiz em 1987 foram sem proteção. Íamos de calções prá vinha [...] Os produtos eram ainda mais perigosos, acho eu [...] Por aqui há doenças de pele, cancros e tudo o que é Alzheimer e doenças neurológicas, há de tudo e eu acho que está tudo ligado. Tudo ligado. São os mais velhos que têm isso, quer dizer os nossos pais. E nós, eu sentia que havia um risco, mas não sabia nada de nada. Foi pouco a pouco que fui procurando estes assuntos e descobri que há ligações" (sócia-gerente 1, 4 de maio de 2018).

Todos os viticultores do Prevexpo estavam a par das informações existentes sobre os efeitos dos pesticidas agrícolas na saúde pública. Todos tinham o Certiphyto, um certificado que atestava possuírem conhecimentos sobre a utilização sustentável dos produtos fitofarmacêuticos. Todos aqueles com quem conviviam no trabalho (vinhateiros, colaboradores, conselheiros técnicos, fornecedores, formadores) e fora do trabalho (amigas/os, pais e filhos) tinham contribuído para aumentar esses conhecimentos. A mediatização da questão dos pesticidas contribuiu também para que se debatesse o assunto, quer entre o grande público (casos de vítimas, de processos contra as empresas em França e no estrageiro) quer entre os atores locais do território. As empresas e os organismos ligados à indústria vitícola local (adegas cooperativas, imprensa especializada, CIVB, Grupos de Defesa contra Organismos Nocivos, Câmara de Agricultura, MSA, sindicatos, associações de vítimas e de moradores, fornecedores de produtos para a agricultura) alertavam os profissionais vitícolas, por exemplo, por meio de boletins informativos, revistas, cadernos de campo, regulamentações, apoios e pressões locais.

Apesar de estarem informados sobre o perigo, todos os profissionais vitícolas estavam envolvidos em situações de risco dos pesticidas relacionadas com a atividade dos tratamentos da vinha. Todos sabiam da existência do perigo dos pesticidas sem necessariamente imaginarem os riscos inerentes à utilização dos produtos fitofarmacêuticos nem terem verdadeira consciência do provável perigo relativo a danos futuros. A análise do discurso e o entendimento da atividade desses profissionais permitiu constatar que eles tinham uma representação longínqua do risco. Por outras palavras, podiam estar a par de uma infinidade de riscos sem, no entanto, se sentirem

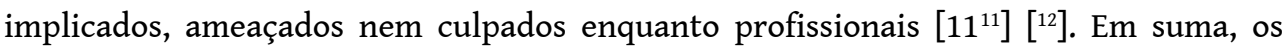
viticultores expunham-se aos pesticidas, ou expunham os outros, mesmo cumprindo escrupulosamente as normas de segurança regulamentares e aplicando as medidas de segurança controlada.

56 A empresária 5 explicou muito bem até que ponto a documentação sobre a exposição aos pesticidas era importante para ajudar os viticultores a protegerem-se durante a utilização de produtos fitofarmacêuticos : "Nos anos 90, estávamos muito longe de ter essas 
informações, estávamos a milhas. De facto, ninguém imaginava o perigo até se conhecerem as estatísticas e os estudos [...] talvez também seja uma sorte haver pessoas assim, que dão o sinal de alarme porque isso alerta também os que são sempre mais teimosos e destemidos... Já nós estávamos alertados e usávamos proteção, e não é que eu vi pessoas sem cabina, completamente azuis ? Sei lá, pr'aí há uns cinco anos ainda havia gente dessa. Teimosos desses" (sócia-gerente 1, 4 de maio de 2018).

57 No entanto, em vários aspetos, a visibilidade dada ao risco dos pesticidas pode ser prejudicial para os viticultores, porque pode aumentar os conflitos de objetivos (por exemplo, tratar das vinhas, combater uma ameaça parasitária, cuidar de si próprio, preservar o meio ambiente, proteger os equipamentos, responder aos pedidos da família ou dos vizinhos, etc.) sem os ajudar a resolver as dificuldades que encontram nas operações de tratamento ou na gestão da sua empresa numa situação de aplicação controlada de pesticidas (utilização e preservação da mão-de-obra num contexto de incerteza, aumento dos custos de produção com a compra de produtos mais eficazes ou com as medidas adotadas em matéria de saúde no trabalho e aconselhamento sobre os pesticidas, etc.). "Não existem alternativas (aos tratamentos fitossanitários), os terrenos não permitem dispensá-los. Uma coisa é ter consciência outra coisa é a prática, há questões económicas e sociais [...] A nossa área de limpeza atual não é top, mas não é uma questão de consciência, é uma questão económica" (E2, 28/06/2018). No dia-a-dia, o que era importante para eles, mais do que a segurança na utilização dos produtos fitofarmacêuticos, era que o produto fosse bem aplicado na planta e na altura certa. Para estarem de boa saúde, pelo menos para cumprirem a missão de responsáveis da exploração agrícola e garantirem a saúde económica da empresa, os empresários agrícolas disseram que aquilo de que precisavam era de apoios para reduzir as incertezas materiais e meteorológicas que os prejudicam.

Com base nas ações realizadas no âmbito do Prevexpo, por exemplo, a análise partilhada das situações de risco dos pesticidas, os empresários vitícolas puderam tornar-se atores da prevenção. O Prevexpo permitiu-lhes tomar consciência da persistência das substâncias ativas (nos equipamentos e nos espaços) e entender, ou melhor, visualizar e tornar evidente um risco pouco percetível. Só quando os profissionais ficaram a conhecer as causas da persistência e da migração dos pesticidas é que se aperceberam dessa realidade e procuraram, eles próprios, encontrar soluções. o "corpo veículo" que contribuiu para a metrologia dos pesticidas, esse corpo em que se deposita a substância que pode passar de uma parte do corpo para outra e para espaços afastados, como o ambiente doméstico, pôde assumir a forma de "corpo atuante" graças à criação de novas práticas para se proteger (Mohammed-Brahim, 2009).

Os empresários vitícolas conceberam, em conjunto, as alterações à escala da estrutura de cada um e da respetiva organização do trabalho, nomeadamente para dar resposta a uma das principais preocupações sentidas : o tempo. $O$ local de preparação da calda foi repensado para se adequar às necessidades de cada um (reorganização dos espaços e dos equipamentos, simplificação das deslocações, redução dos armazenamentos, aperfeiçoamento da recolha de informação, redução da circulação dos produtos em pó, do stress térmico e da exposição cutânea). Depois de conhecerem as situações de risco no desempenho da sua atividade, os profissionais tentaram descobrir de que forma podiam limitar os contactos com os pesticidas, não só os deles, mas também os do seu círculo próximo. Assim, reservaram equipamentos e espaços específicos para as operações de tratamento (instalando uma canalização de água exclusivamente 
destinada aos tratamentos fitossanitários). Partilharam as soluções para proteger a cabina do trator da contaminação dos pesticidas. Tentaram também separar objetos pessoais e equipamentos e (re)organizar os espaços e os tempos de trabalho.

Quando se reuniram, os viticultores expuseram os obstáculos que enfrentavam e tentaram descobrir a forma de contornar esses constrangimentos impostos à sua atividade. Foi a partir dessas condicionantes comuns, decorrentes da construção territorial da sua atividade, que discutiram as dificuldades que cada um tinha ao tentar conciliar a atividade produtiva com a proteção individual. Essa reunião deu-lhes oportunidade de partilharem estratégias para diminuírem a ocorrência de situações críticas provocadas pelos sistemas de produção, de conceção e de prevenção controlada. O Prevexpo, concretamente, permitiu-lhes tentar encontrar, sozinhos ou com a ajuda de outros parceiros, a forma de transformar os equipamentos de tratamento e de proteção (recipientes dos produtos fitofarmacêuticos, EPI, tanques de incorporação, etc.) (ver Goutille, 2022). Criaram novas vias de transformação a explorar a vários níveis : vias a explorar ou a desenvolver num tempo limitado para responder aos problemas atuais; vias a explorar a médio prazo para evitar problemas futuros; vias para dar resposta a condicionamentos mais ou menos prioritários ou menos complexos; vias de transformação que permitem que se atue sozinho ou que exigem a participação de parceiros que ajudem na conceção.

Prevexpo, a conciliação entre as preocupações dos empresários agrícolas e as dos ergonomistas veio pôr em causa a abordagem ergotoxicológica e, de um modo geral, as experiências democráticas sobre o papel da investigação da ergonomia quando se trata de pôr em ação as pessoas e os coletivos. No âmbito desta reflexão, a documentação dos constrangimentos sentidos pelos empresários vitícolas em termos operacionais tem por objetivo convencer os decisores, e os autores, "todos prescritores do trabalho dos agricultores" (ibid.), de que é fundamental melhorar o que já existe não só em termos de prevenção do risco dos pesticidas, mas, mais amplamente, em termos de promoção da saúde na agricultura. Assim, a intervenção ergonómica, ao estabelecer uma ligação entre o operacional e o estrutural, procura contribuir para uma conceção de "ambientes de trabalho abertos à discussão", onde as "descobertas diárias" dos empresários vitícolas são discutidas e podem ser integradas na estrutura de forma a que essa conceção se mantenha em prática" (Arnoud \& Falzon, 2013, p. 226).

o facto de a análise se centrar nas pessoas em atividade permitiu examinar os constrangimentos atuais e históricos da atividade de tratamento : resposta química às infestações imposta aos profissionais ou aos seus antepassados; mecanização a que se seguiram as novas tecnologias para garantir o rendimento e consolidar uma agricultura de precisão; responsabilização pela exposição aos pesticidas com obrigação de indemnizar as vítimas e de reduzir a poluição difusa ; constante regulamentação nova que exige uma transformação da exposição (investindo em novos equipamentos, substituindo os produtos CMR, criando barreiras vegetais, reduzindo as áreas de tratamento, equipando os assalariados, etc.) ; exigências dos moradores, consumidores e organismos profissionais vitícolas, por exemplo, para que preservem a paisagem, reduzam os tratamentos, produzam melhor, pratiquem preços atrativos e criem produtos de valor ambiental elevado.

63 Incluir a dinâmica que "envolve o indivíduo no seu todo com o seu corpo biológico, a sua inteligência, a sua afetividade, ao longo da sua história e nas suas relações com os outros" (Teiger, 1993, p. 80), permitiu compreender que a documentação das exposições 
viabilizada pela análise ergonómica podia contribuir para constranger mais ou menos diretamente as pessoas com quem se estava a construí-la. Isso podia contribuir para provar a existência dum perigo ou dum risco para a população e para o ambiente, e essa documentação podia ser instrumentalizada (pelas empresas no Forumphyto, pelas associações de vítimas que pedem indemnizações e reconhecimento de doença profissional, pelos fabricantes que procuram desenvolver-se, pelos investigadores que tentam obter provas, etc.). Essa documentação podia provocar novas mobilizações da sociedade civil, envolvimento dos organismos profissionais vitícolas ou novas medidas que acabariam por se traduzir em novas regulamentações dirigidas aos empresários vitícolas. Ao não incluir a origem das exposições, os dados sobre estas obtidos podiam contribuir para a reprodução de um sistema de gestão de risco dos pesticidas assente em dispositivos normativos, materiais e regulatórios que se sabe não bastarem para ajudar os viticultores a protegerem-se das exposições com dignidade.

Ao longo do Prevexpo, foi possível observar como a gestão por "boas práticas" dos utilizadores, fundamental em muitos dispositivos de utilização controlada do risco dos pesticidas, não ajudou os empresários vitícolas a construir uma prevenção do risco. Pelo contrário, ao interiorizarem esse quadro, os empresários vitícolas podiam associar as intoxicações a um erro profissional, à falta de experiência dos jovens, erros que eles, enquanto responsáveis, devem remediar correndo riscos. Chegam a sentir-se culpados das intoxicações de que são vítimas, ou de que são vítimas os seus assalariados, e a considerar que elas fazem parte dos inconvenientes diários do seu trabalho (Nicourt, 2016). A obtenção de informação sobre a exposição a pesticidas não devia servir para alimentar a produção de regulamentações que atribuem um papel central às barreiras de proteção (uso de EPI, formações obrigatórias como o Certiphyto, etc.), que individualizam responsabilidades coletivas e ocultam a dimensão sistémica e territorial da utilização dos produtos fitofarmacêuticos.

65 A forma como o viticultor vai construir o seu ecossistema (empregar este ou aquele produto de tratamento, com esta ou aquela frequência, com este ou aquele equipamento, etc.) depende, simultaneamente, das componentes ditas "naturais" do meio ambiente (meteorologia e clima) e das componentes sociais (castas plantadas, traçado da vinha, modo de produção, regulamentações, etc.). Estas componentes sociais inscrevem-se na história e na dinâmica dum território mais vasto que ultrapassa o da empresa.

66 A pessoa que desempenha a atividade tem de conviver com tudo e todos os que a rodeiam (família, vizinhos, conselheiros, outras profissões, sindicatos, cientistas, empresas, etc.). No que diz respeito aos tratamentos fitossanitários, os empresários vitícolas, em particular, têm de lidar com condicionantes e dinâmicas ocultadas pelas pressões exercidas a diferentes níveis (Béguin et al., 2011). Aqui, a unidade de análise já não é apenas o tratamento em si, mas também o(s) território(s) e a dinâmica de trabalho e de vida daqueles com quem a pessoa (cuja atividade se pretende conhecer) tem de contactar (ver Figura 6). Trata-se, portanto, de entender de que forma a pessoa em questão, ao construir a sua atividade de tratamentos fitossanitários, integra as dimensões (sociais, económicas, regulamentares, tecnológicas, etc.) que ultrapassam a operação em si. De que forma é que essas dimensões que ultrapassam a situação do trabalho, que os instrumentos disponíveis permitem conhecer, podem ser documentadas e (re)formuladas pelas próprias pessoas que desempenham a essa atividade. 
Figura 6 : Análise da atividade a diferentes escalas para compreender as situações de risco e as condições que lhes dão origem com as pessoas em atividade
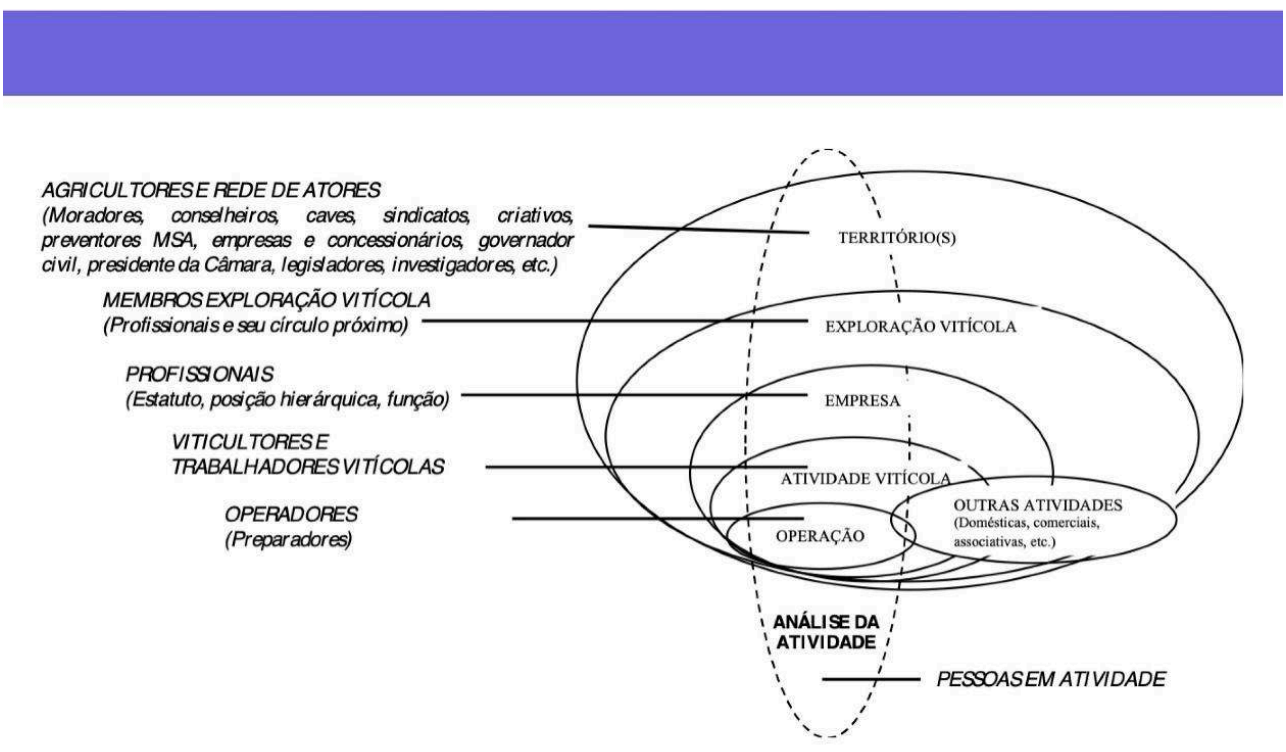

Figura 6: Análise da atividade a diferentes escalas para compreender as situações de risco e as condições que Ihes dão origem com as pessoas em atividade.

Figura 6 : Análise da atividade a diferentes escalas para compreender as situações de risco e as condições que lhes dão origem com as pessoas em atividade

67 O programa Pestexpo (ver Baldi et al., 2012) [13], ao efetuar a análise da atividade, demonstrou que o grau de contaminação das pessoas "varia consideravelmente em função do estado do equipamento utilizado: tipo de cabina, tipo de pulverizador, acondicionamento dos produtos no momento da preparação das caldas, etc. Quanto mais antiquado for o equipamento maior o número de fontes de contaminação, sobretudo quando há intervenções técnicas para resolver avarias" (Jouzel, 2019, p. 180). A análise multi-escalar realizada ao longo do Prevexpo mostra que são também os progressos tecnológicos, as condicionantes territoriais e as obrigações ambientais que podem desencadear situações de risco dos pesticidas para os viticultores. A deslocação da representação da exposição e dos seus fatores aqui proposta é importante. Sem pôr de novo em causa a responsabilidade dos empresários vitícolas na origem das exposições, a referida deslocação abre caminho para uma análise dos fatores sistémicos da utilização de produtos fitofarmacêuticos.

Num contexto de utilização controlada de pesticidas, a intervenção ergonómica deve também ser realizada ao nível do sistema de produção, de conceção e de prevenção que mantém os viticultores na sua dependência, restringe a sua atividade e ignora a sua capacidade de inovação. Para que não sejam os empresários vitícolas os únicos responsáveis pelas transformações a efetuar (para reduzir as exposições aos pesticidas), os resultados da investigação-intervenção apontam para o desenvolvimento duma análise e duma ação ergonómica sistémica que interligue macro e microdeterminantes das situações de risco dos pesticidas. Nessa perspetiva, as ações de transformação podem ser pensadas com as pessoas que desempenham a atividade e realizadas complementarmente ao nível da empresa e ao nível do território. 


\section{Conclusão} distantes das explorações agrícolas a contribuírem para o desenvolvimento da saúde dos agricultores. Nestas circunstâncias, o território constitui uma escala fundamental para se estabelecer o diálogo e criar dispositivos que permitam articular os desafios da preservação do ambiente, do desenvolvimento económico e do desenvolvimento das pessoas através do seu trabalho. A intervenção ergonómica nas suas diferentes dimensões - reflexiva, prospetiva e projetiva - pode desempenhar aí um papel decisivo. Resta discutir a forma de articulação da ergonomia com outras disciplinas para permitir que a ação coletiva intervenha em diferentes níveis.

72 Este número especial da Laboreal, sobre a atividade de trabalho, o território e os seus protagonistas constituiu uma oportunidade para revisitar os resultados do projeto Prevexpo. Veio dar continuidade à análise dos macrodeterminantes das exposições aos pesticidas e possibilitar o estudo das questões ligadas à prevenção dos riscos dos pesticidas com origem à escala do território francês e que se revelam no exercício da atividade de trabalho. Abre caminho a inúmeras perspetivas de desenvolvimento da ergotoxicologia com vista a contribuir para a prevenção do risco químico. Nesta mesma linha, os autores retomaram os trabalhos de Boudra et al. (2016) que levantaram a questão do papel do território, ou dos territórios, na génese de macro ou mesodeterminantes que acabam por se enraizar nas situações de trabalho e que, de facto, passam a ser determinantes da atividade de trabalho. 


\section{BIBLIOGRAFIA}

Arnoud, J., \& Falzon, P. (2013). La co-analyse constructive des pratiques. In P. Falzon (ed.), Ergonomie constructive (pp. 223-236). Paris : Presses Universitaires de France. https://doi.org/ 10.3917/puf.falzo.2013.01.0223

Aubertot, J., Barbier, J., Carpentier, A., Gril, J., Guichard, L., Lucas, P., ... Voltz, M. (2005). Pesticides, agriculture et environnement. Réduire l'utilisation des pesticides et limiter leurs impacts environnementaux. Rapport d'Expertise scientifique collective, INRA e CEMAGREF.

Baldi, I., Botton, J., Chevrier, C., Coumoul, X., Elbaz, A., Goujon, S., Jouzel, J.N., ... Spinosi, J. (2021). Pesticides et effets sur la santé : Nouvelles données. Inserm. Collection Expertise collective.

Montrouge : EDP Sciences.

Béguin, P., Dedieu, B., \& Sabourin, E. (2011). Le travail en agriculture : son organisation et ses valeurs face à l'innovation. Paris : L'Harmattan.

Bellemare, M., Montreuil, S., Marier, M., Prévost, J., \& Allard, D. (2001). L'amélioration des situations de travail par l'ergonomie participative et la formation. Relations Industrielles, 56(3), 459-479. https://doi.org/10.7202/000079ar

Bobillier Chaumon, M-E., Rouat, S., Laneyrie, E., \& Cuvillier, B. (2018). De l'activité DE simulation à l'activité EN simulation : simuler pour stimuler. Activités, 15(1). https://doi.org/10.4000/ activites.3136

Boudra, L., Delecroix, B., \& Béguin, P. (2016). Mobiliser une approche développementale dans l'intervention ergonomique. Réflexions sur la démarche d'action et la posture de l'intervenant. In 3ème Congrès de la Société Internationale d'Ergologie. Aix-en-Provence.

Candau, J., Ginelli, L., Goutille, F., \& Garrigou, A. (a publicar). Capacités d'initiative et d'expression des travailleurs agricoles sur la transition écologique relative aux pesticides. Rapport final CITTEP - Cit'in Expérimentations démocratiques pour la transition écologique.

Caroly, S., \& Weill-Fassina, A. (2004). Évolutions des régulations de situations critiques au cours de la vie professionnelle dans les relations de service. Le Travail Humain, 4(4), 305-332. https:// doi.org/10.3917/th.674.0305

Cuvelier, L. \& Woods, D. (2019). Sécurité réglée et/ou sécurité gérée : quand l'ingénierie de la résilience réinterroge l'ergonomie de l'activité. Le Travail Humain, 82(1), 41-66. https://doi.org/ $10.3917 /$ th.821.0041

Galey, L., \& Garrigou, A. (2020). La ergotoxicología, de la palabra a los conceptos y metodologías. Laboreal, 16(2). https://doi.org/10.4000/laboreal.16402

Galey, L., Judon, N., Goutille, F., Jolly, C., Albert, M., Morelot, S., ... Garrigou, A. (2019). Proposition méthodologique en ergotoxicologie pour révéler les expositions à des produits chimiques. Activités, 16(1), 1-27. https://doi.org/10.4000/activites.4103

Garrigou, A., Baldi, I., Mohammed-Brahim, B., Jackson, M., Ullilen Marcilla, C., Lefevre, L., \& Pasquereau, P. (2012). L'usage des pesticides en France : un transfert de technologie mal maîtrisé ? In Actes du 47ème Congrès de la SELF. Lyon : SELF.

Gatignol, C., \& Étienne, J.C. (2010). Rapport sur Pesticides et Santé. Office Parlementaire d'Évaluation des Choix Scientifiques et Technologiques. Retirado de https://www.senat.fr/rap/r09-421/r09-421.html 
Goutille, F., Galey, L., Rambaud, C., Pasquereau, P., Jackson Filho J., \& Garrigou, A. (2016). Prescrição e utilização de equipamentos de proteção individual (EPI) em atividades com exposição a produtos químicos cancerígenos, mutagénicos e reprotóxicos (CMR) : pesquisa-ação pluridisciplinar em uma fábrica francesa de decoração para móveis. Laboreal, 12(1), 23-38. https:// doi.org/10.4000/laboreal.2930

Jas, N. (2010). Pesticides et santé des travailleurs agricoles en France. Questions anciennes, nouveaux enjeux. Le Courrier de l'environnement de l'INRA, 59, 47-59. https://hal.archivesouvertes.fr/hal-01196933/file/C59Jas.pdf

Jouzel, J. (2019). Pesticides : Comment ignorer ce que l'on sait. Paris : Presses de Sciences Po. Laurent, C., Baldi, I., Bernadac, G., Berthet, A., Colosio, C., Garrigou, A., ..., Wavresky P. (2016). Expositions professionnelles aux pesticides en agriculture. Agence Nationale de Sécurité Sanitaire de l'Alimentation, de l'Environnement et du Travail.

Leplat, J. (2008). Repères pour l'analyse de l'activité en ergonomie. Paris : PUF.

Mohammed-Brahim, B. (2009). Travailler en présence de substances toxiques : un corps à corps au quotidien. Corps au Travail, 6(1), 53-59. https://doi.org/10.3917/corp.006.0053

Mohammed-Brahim, B. (2011). L'ergotoxicologie : un modèle opérant pour la prévention du risque chimique. Retirado de https://www.youtube.com/watch ?v =XwVC1nTYPnk

Morel, G., Amalberti, R., \& Chauvin, C. (2008). Articulating the Differences Between Safety and Resilience: The Decision-Making Process of Professional Sea-Fishing Skippers. Human Factors: The Journal of the Human Factors and Ergonomics Society, 50, 1-16. https://doi.org/

$10.1518 / 001872008 X 250683$

Moscovici, S. (2000). Ideas and their development: a dialogue between Serge Moscovici and Ivana Marková. In S. Moscovici, \& G. Duveen (Dir.), Social Representations (pp. 224-286). Cambridge : Cambridge University Press.

Nascimento, A., Cuvelier, L., Mollo, V., Dicciocio, A., \& Falzon, P. (2013). Construire la sécurité : du normatif à l'adaptatif. In P. Falzon (Dir.), Ergonomie constructive (pp. 103-116). Paris : PUF.

Nicourt, C. (2016). Les mobilisations des victimes de pesticides ont-t-elles modifié les pratiques des viticulteurs languedociens? Vertig0 16(1). https://doi.org/10.4000/vertigo.17070

Oddone, I. (1984). La communauté scientifique élargie. Revue Société Française, 10, 28-33.

Pueyo, V. (2020). Pour une Prospective du Travail. Les mutations et transitions du travail à hauteur d'Hommes. Anthropologie sociale et ethnologie. Université Lumière Lyon 2.

Re, A., Callari, T., \& Occelli, C. (2014). Sfide attuali, passate, future : il percorso di Ivar Oddone. Torino : Otto Editore.

Teiger, C. (1993). L'approche ergonomique : du travail humain à l'activité des hommes et femmes au travail. Éducation Permanente, 116(3), 71-96.

Vinck, D. (2003) L'instrumentation du travail interdisciplinaire : cadrage des échanges et médiation par les objets intermédiaires. Esprit Critique : Revue Internationale de Sociologie et de Sciences Sociales, 5(1). 


\section{NOTAS}

1. FranceAgriMer é o organismo nacional dos produtos agrícolas e do mar. Os números aqui apresentados provêm de Synthèses de FranceAgriMer: Vins et spiritueux Commerce extérieur Bilan 2018. Março de 2019, nº 52

2. Gatignol e Étienne (2010) dizem, por exemplo, que $90 \%$ das 78.000 toneladas vendidas em 2018 se destinaram a utilização na agricultura.

3. Trata-se, por exemplo, da obrigatoriedade de tratamento contra certos parasitas (Code Rural) [legislação fundiária], da proibição de fazer tratamentos durante as épocas de reprodução das abelhas (Code de l'environnement) [legislação ambiental], de áreas de não tratamento (próximas dos moradores), de prazos de tratamento antes da colheita, de prazos para o regresso do pessoal às parcelas depois do tratamento, da limitação da dispersão dos pesticidas (força do vento no momento da aplicação, condições de armazenamento, de mistura e de eliminação dos produtos durante a preparação), de regras de higiene e segurança (por exemplo, uso obrigatório de EPI adequados durante o manuseamento dos produtos fitofarmacêuticos), da formação do pessoal, da adaptação dos locais às normas (Código do Trabalho) e da certificação do equipamento de tratamento.

4. Foi possível constatar que, ao longo dos últimos anos, todas as empresas tinham evoluído para uma escolha de substâncias activas não CMR ou menos perigosas (E0, E1, E2, E3, E4, E5), tinham adaptado as áreas de preparação às normas (E0, E1, E4, E5), tinham melhorado ou procurado melhorar o Documento Único de Avaliação de Riscos (E0, E1, E5 ), tinham criado fichas de dados de segurança no posto de trabalho (E0, E1), tinham afixado cartazes com normas de segurança (E0, E1, E5), tinham instalado um vestiário ou um armário para EPI (E0, E1, E2), tinham investido num pulverizador com cabina pressurizada (E1), tinham fornecido ou comprado novos EPI (E0, E1, E4).

5. A dimensão contextual da actividade, cuja análise aqui se propõe, faz referência aos trabalhos de Catherine Teiger (1993) sobre a dimensão situada da actividade. "Entende-se por contexto quer o ambiente material quer organizacional e relacional do ou dos operadores, a relação social, sendo o salariado, por exemplo, uma das carecterísticas das condicionantes do contexto, e também o contexto sócio-económico geral. o contexto é analisado na medida em que induz condicionantes, mas também recursos para a actividade. No entanto, é sobretudo como condicionante que surge na investigação ergonómica, a maior parte das vezes centrada na compreensão das dificuldades do exercício da actividade e das suas consequências em termos de saúde e/ou emprego. o contexto de trabalho inclui também o fora-do-trabalho. Com efeito, o fora-do-trabalho é o local de repercussão das actividades de trabalho (profissional) - quanto mais não seja em termos de estado de fadiga e de preocupação - e o local de produção de trabalho (doméstico), sendo que, por outro lado, as repercussões das condições de vida fora do trabalho se manifestam nas actividades de trabalho, cada um domínios assumindo o seu significado em relação ao outro e articulando-se ambos entre si." (Teiger, 1993, p. 79)

6. As medidas definidas, a nível europeu, pela última PAC (2021) vieram apoiar os anseios do maior sindicato agrícola de França (FNSEA). A PAC continuará a ser, nos próximos anos, "uma política económica destinada a, tal como prevêm os Tratados europeus, estabilizar e manter os rendimentos dos agricultores ao mesmo tempo que se adapta aos desafios ambientais da actualidade" (FNSEA, 2021). A FNSEA e outros grandes sindicatos agrícolas de Itália e da Alemanha (a Confagricoltura e o DBV), "defendem uma PAC mais verde, gerível e atractiva para os agricultores, e também mais eficaz" (ibid.) 
7. Convém lembrar que o CIVB (Conselho Interprofissional do Vinho de Bordéus) envolve 5.800 viticultores (produtores de Denominação de Origem Controlada de Bordéus) de um conjunto de 7.000 empresas inscritas, numa região vinícola com 111.400 hectares de vinha, ou seja, 1/4 da área dos vinhos DOC franceses. As cotizações anuais foram calculadas em mais de 29 milhões de euros (en 2010), um dos montantes mais elevados do conjunto dos conselhos interprofissionais regionais e nacionais franceses.

8. As distâncias de protecção são calculadas em função da toxicidade dos produtos fitofarmacêuticos utilizados, do tipo de cultura e do tipo de equipamento utilizado. A distância de protecção varia entre 5 e 100 metros, ou mais, conforme a estimativa do impacto do produto sobre os espaços. Nalguns casos, a aplicação pode voltar a ser feita numa ZNT de $5 \mathrm{~m}$ com produtos próprios para uma ZNT de 20 ou 50 metros e, assim sendo, a empresa menciona as práticas de tratamento num registo específico, instala na ZNT um dispositivo vegetalizado, recorre a uma técnica para reduzir a deriva da pulverização; estas medidas têm de constar do Boletim Oficial do Ministério da Agricultura e da Alimentação. Só os produtos homologados pelo Ministério (lista de 27 de Fevereiro de 2020), reconhecidos como capazes de reduzir a deriva em, pelo menos, $66 \%$, nomeadamente, o material Optibuse ${ }^{\circledR}$ fabricado pela empresa Syngenta ${ }^{\circledR}$, permitem não respeitar as distâncias mínimas fixadas de acordo com a indicação do grau de toxicidade dos produtos.

9. Responsáveis pela exploração vitícola, viticultores associados ou assalariados sindicalizados, militantes ou membros de associações que tenham como objectivo alertar para o perigo ou apoiar as vítimas.

10. Cancro, leucemia, doença de Parkinson ou da tiróide, hipersensibilidade aos químicos, malformação congénita, etc.

11. Uma substância activa, um produto comercial, as condições de trabalho, o ambiente humano, o número de anos de exposição aos pesticidas, etc.

12. Disseram, por exemplo, que dantes era pior (nem cabina nem vestuário de protecção) ou que era pior na região de onde vinham (por exemplo, na Charente-Marítima onde "deixam a vinha a sangrar" como refere o empresário 2). Alguns dizem que não há problemas de fertilidade na família ou que já não se preocupam com a necessidade de ter filhos. Muitos salientaram o facto de terem criado práticas agro-ecológicas, investido em novas tecnologias ou inventado truques e artifícios para evitar o perigo. Referiram, também, a lei e a legalidade das suas práticas. Os produtos utilizados estavam "homologados" e era "legal" estar a podar a vinha (estágio na E2 a 5 de Abril de 2018) ao mesmo tempo que na propriedade do lado estavam a fazer a deservagem com Roundup. Ninguém estáva a manipular fitofármacos, nem a regressar à vinha.

13. O estudo da Pestexpo (realizado por Baldi et al. na década de 2000) observou os níveis e determinantes da exposição a agrotóxicos entre os operadores envolvidos no tratamento da videira. Os resultados do estudo estão disponíveis na Journal of Exposure Analysis and Environmental Epidemiology. J Expo Sci Environ Epidemiol. 2012 Aug 15, http://www.ncbi.nlm.nih.gov/pubmed/ 22892809

Laboreal, Volume $17 \mathrm{~N}^{\circ} 2$ | 2021 


\section{RESUMOS}

O trabalho apresentado neste artigo explora as relações entre atividade, exposição aos pesticidas e território, apelando para o campo de ação da ergonomia a fim de agir de forma preventiva.

A atividade do tratamento fitossanitário (proteção das culturas com recurso ao uso de produtos fitofarmacêuticos) foi inicialmente estudada para documentar a exposição a pesticidas dos viticultores em condições reais de trabalho. Os trabalhos de reflexão realizados com os empresários vitícolas levaram a que se estabelecesse uma relação entre a atividade de tratamento e os mecanismos e práticas sociais que regem a organização nacional e local da utilização de produtos fitofarmacêuticos em meio vitícola. A articulação destes dois níveis de análise da atividade (atividade laboral e construção territorial da atividade) permitiu ver de que forma o contexto territorial nacional e local (social, político e histórico) pode impedir a dimensão construtiva da prevenção do risco dos pesticidas. 0 artigo propõe-se acompanhar os viticultores na recuperação do controlo do seu trabalho através de ações ergonómicas ao nível da empresa e do território.

El trabajo presentado en este artículo explora las relaciones entre actividad, exposición a los pesticidas y territorio, apelando para el campo de acción de la ergonomía de cara a actuar de forma preventiva.

Se estudió inicialmente la actividad del tratamiento fitosanitario (protección de los cultivos empleando productos fitosanitarios) para documentar la exposición de los viticultores a los pesticidas en condiciones reales de trabajo. Los trabajos de reflexión realizados con los empresarios vitícolas llevaron a que se estableciera una relación entre la actividad de tratamiento y los mecanismos y prácticas sociales que rigen a la organización nacional y local de la utilización de productos fitofarmacéuticos en el medio vitícola. La articulación de estos dos niveles de análisis de la actividad (actividad laboral y construcción territorial de la actividad) ha permitido ver de qué forma el contexto territorial nacional y local (social, político e histórico) puede impedir la dimensión constructiva de la prevención del riesgo de los pesticidas. El artículo se propone acompañar a los viticultores en la recuperación del control de su trabajo mediante acciones ergonómicas a nivel de la empresa y del territorio.

Le travail présenté dans cet article vient explorer les relations entre activité, , exposition aux pesticides et territoire tout en interrogeant le champ d'action de l'ergonomie pour agir en prévention. L'activité de traitement phytosanitaire (protection des cultures par l'usage de produits phytopharmaceutiques) a premièrement été étudiée pour documenter les expositions aux pesticides des exploitants viticoles dans les conditions réelles de travail. Les activités réflexives menées avec les exploitants nous ont ensuite amenés à relier l'activité de traitement aux mécanismes et pratiques sociales qui commandent l'organisation nationale et locale de l'usage des produits phytopharmaceutiques en milieu viticole. Relier ces deux niveaux d'analyse de l'activité (activité de travail et construction territoriale de l'activité) nous a permis d'observer comment le contexte territorial (social, politique et historique) national et local peut venir empêcher la prévention du risque pesticides dans sa dimension constructive. L'article propose d'accompagner les exploitants viticoles dans la reprise en main de leur travail par une action ergonomique à l'échelle de l'entreprise et du territoire.

The work described in this article explores the relationships between activity, the exposure to pesticides, and territory, drawing on the field of action in ergonomics for preventive measures. The phytosanitary treatment activity (crop protection using phytopharmaceutical products) was initially studied with the objective of documenting the exposure to pesticides by wine producers 
under real working conditions. Discussions with business owners led to the establishment of a relationship between the processing activity carried out, and the mechanisms and social practices which define the national and local organization of the use of phytopharmaceutical products in the wine producing context.

The interconnection of these two levels of activity analysis (work activity and territorial construction of activity) made it possible to see how the national and local territorial context (social, political and historical) can hinder the constructive dimension of pesticide risk prevention. The article follows winegrowers during the process of regaining control of their work through ergonomic actions at both the company and territory levels.

\section{ÍNDICE}

Palabras claves: análisis del trabajo, exposición de los profesionales, territorio, pesticidas, viticultura

Mots-clés: analyse du travail, exposition professionnelle, territoire, pesticides, viticulture Palavras-chave: análise do trabalho, exposição dos profissionais, território, pesticidas, viticultura

Keywords: work analysis, professional exposure, territory, pesticides, viticulture

\section{AUTORES}

\section{FABIENNE GOUTILLE}

https://orcid.org/0000-0001-8038-4814

Université de Bordeaux, Inserm, Bordeaux Population Health Research Center, Equipe EPICENE, UMR 1219, 146 rue Léo Saignat, 33000 Bordeaux

fabienne.goutille@gmail.com

\section{ALAIN GARRIGOU}

https://orcid.org/0000-0002-7467-0643

Université de Bordeaux, Inserm, Bordeaux Population Health Research Center, Equipe EPICENE, UMR 1219, 146 rue Léo Saignat, 33000 Bordeaux

alain.garrigou@u-bordeaux.fr 